\title{
LOS PASAJES DE NEBRIJA SOBRE LOS CECEOSOS
}

En un par de ocasiones Nebrija se refirió a la pronunciación de los ceceosos. Amado Alonso fue quien sacó a luz estas indicaciones $^{1}$; al llorado maestro las palabras de Nebrija le resultaron totalmente enigmáticas y optó por descalificarlas, declarando que el gran humanista no observaba y sí, en cambio, era amigo de la erudición libresca (cf. infra § 1). Sosteniendo una tesis distinta, Diego Catalán se ocupó posteriormente de estas referencias a los ceceosos y consideró que los personajes así calificados eran los sevillanos ${ }^{2}$; después, esos pasajes de Nebrija han quedado olvidados o relegados a la oscuridad. Por mi parte, siempre he creído que Nebrija no podía estar diciendo desatinos; además, las categorías de "observador-libresco" no me parecían apropiadas para la filología del Renacimiento. Insatisfecho con la explicación de Alonso, y no pudiendo compartir tampoco la tesis de Catalán, he ido reuniendo en el curso de mis lecturas las noticias que pudieran dar luz sobre esos pasajes de Nebrija. Las presento ahora en estas páginas, sin más deseo que mostrar que las indicaciones sobre los ceceosos se hacen plenamente inteligibles si se las coloca dentro de la tradición intelectual en que han sido pensadas. No son descripciones fonéticas ni precisiones dialectológicas; son observaciones sobre sonidos que tienen como marco de referencia una cuestión de la filología bíblica de la época.

1 "Examen de las noticias de Nebrija sobre antigua pronunciación española", $N R F H, 3$ (1949), pp. 22 y 60 . En adelante citaré este trabajo abreviando su título en "Nebrija". Aprovecho esta nota inicial para dejar constancia de mi agradecimiento a los bibliotecarios de la Houghton Library y de la Andover-Harvard Theological Library, ambas de Harvard University, por la amabilidad sin desmayos con que me atendieron en el curso de este estudio.

2 "El çeçeo-zezeo al comenzar la expansión atlántica de Castilla", $B d F$, 16 (1956-1957), 323-328. En adelante: "El çeçeo-zezeo". 


\section{LAS EQUIVALENCIAS ESP. $C=$ LAT. $S=$ HEBR. $S A M E C$}

En su gran ambición de restituir su pronunciación legítima a las letras que la habían perdido durante los siglos de la barbarie, Nebrija se vio llevado a enfrentarse a principios del siglo XVI con el caso de la $s$. En sus trabajos del siglo Xv no había pensado que hubiera un problema en este punto y estimaba que la $s$ de los modernos tenía el mismo sonido que la de los antiguos; cuando hacia fines de la centuria se dedicó a los estudios bíblicos ${ }^{3}$ debe ha-

3 Pedro Lemus y Rubio, "El maestro Elio Antonio de Lebrixa, 1441?1522"', RHi, 22 (1910), p. 470; FÉlix G. Olmedo, Nebrija (1441-1522), Editora Nacional, Salamanca, 1942, p. 127; Marcel Bataillon, Erasmo y Espa$\tilde{n} a, 2^{a}$ ed., F.C.E., México, 1966, p. 26. Bataillon piensa que, “a juzgar por el giro que toman sus investigaciones bíblicas, nos sentimos tentados a creer que éstas se originaron en sus conversaciones con sabios judíos [de la corte de don Juan de Zúñiga], que por su solo conocimiento del hebreo debieron darle la solución de ciertos enigmas de la Vulgata"'. Esta conjetura me parece infundada e innecesaria. Los "sabios de origen judio" en conversación con los cuales se habría despertado en Nebrija el interés por los estudios bíblicos, resultan ser, según la n. 16 a que envía el ilustre estudioso, uno solo, Abraham Zacuto, que por añadidura era astrónomo. La presencia de Zacuto en la corte del Maestre de Alcántara, por otra parte, no pasa de ser una hipótesis, como señalan los estudios de Carvalho y Cantera a que se remite Bataillon. En cuanto a que los judíos (el judío) por su conocimiento del hebreo pudieran haberle dado la solución de enigmas léxicos de la Vulgata, tenemos en contra el testimonio de Nebrija, que a propósito de sus soluciones a esos enigmas escribe: "meo iure possum vindicare, quod vigilijs atque laboribus meis sum assecutus" (Apologia earum rerum quae illi obijciuntur, Arnao Guillén de Brocar, Logroño, 1507, f. b i $r^{\circ}$ ); piénsese, además, que si los judíos le hubieran dado la solución, sería porque Nebrija ya tenía el problema, es decir, que la inquietud de Nebrija por cuestiones bíblicas sería anterior a su trato con ellos, no su consecuencia. En fin, a finales del siglo xv, en una época de fervor religioso y en que la crítica textual de la Biblia ya había sido iniciada por Valla, resulta totalmente forzado querer poner el origen de sus intereses bíblicos en una presunta y pasajera relación con un astrónomo hebreo. Hoy inclusive sabemos que debió haber tenido inclinaciones religiosas en su juventud, pues entró en el Colegio de Bolonia como teólogo y todavía en 1468 conservaba esta categoría; cf. LuIS GiL, "Nebrija en el Colegio de los Españoles en Bolonia", Em, 33 (1966), p. 349. La posición de Francisco Rico, Nebrija frente a los bárbaros, Universidad, Salamanca, 1978, p. 64, que coloca el aprendizaje del hebreo de Nebrija demro de la "dinámica interna del humanismo", es sin duda la acertada. GARCía DE LA CONCHA, "La impostación religiosa de la reforma humanística en España: Nebrija y los poetas cristianos", Actas de la III Academia literaria renacentista, Universidad, Salamanca, 1983, p. 134, acepta la tesis de Bataillon y en cierto modo la amplía, indicando que "su conjetura de influencia de intelectuales judeo-conversos se hace evidente en la confesión del propio autor de 
ber conocido el tratado de San Jerónimo De nominibus Hebraicis, en el cual expone el santo las características de las sibilantes hebreas frente a la $s$ latina:

[...] apud hebreos tres s sunt litterae: una quae dicitur samech, et simpliciter legitur quasi per s nostram litteram describatur: alia sin, in qua stridor quidam non nostri sermonis interstrepit; tertia sade, aures nostrae penitus reformidant ${ }^{4}$.

En este famoso pasaje San Jerónimo sentaba que la $s$ latina sonaba como el samec hebreo. Para Nebrija, el samec correspondía a la $\varsigma$ castellana, de manera que, de acuerdo con lo que decía San Jerónimo, la $s$ latina (en cuanto igual al samec) venía a equivaler a la $\varsigma$ del castellano, no a su $s$. Por este camino Nebrija concluye que los modernos, que dan a la $s$ el sonido del sin, están pronunciando mal esa letra. Bueno, no todos los modernos; no sin cierta sorpresa Nebrija viene a descubrir que los ceceosos, esa gente que pronuncia defectuosamente la $s \operatorname{como} \xi$, son los únicos que dan su sonido legítimo a la $s$. He aquí los pasajes de Nebrija:

Nam quas in huius litterae $[s]$ prolatione fieri delicias prohibet Quintilianus, ego non intelligo. Ex omnis igitur his rationibus satis constat $s$ littera quem sonum readere debeat, hoc est, non eum quem Galli $c$ $e$ vel $i$ sequentibus atribuunt, cum $s$ littera confundentes, sed eum potius quem genus quoddam hominum ceceosos Hispani vocant, non sine quadam offensionis levissimae venustate. Quemque [sonum], occupanti bus Galaaditis vada Iordanis, ut in Libro ludicum scri-
Fuit tempus quo et putabam hanc litteram [s] tali sono debere proferri quali nunc imperitum vulgus enuntiat et quas in illius prolatione delicias fieri prohibet Quintilianus coniectabam illorum esse quos vulgo Hispani ceceosos vocant: nunc vero, his rationibus quas supra attulimus convicti, asseveramus illos recte, nos perperam hodie hanc litteram pronunciare, ut qui solebant a nobis derideri possint nos vicissem iure suo eludere. Sed nos illos hoc una in re superamus:

la Apologia: "Nam quod de iudaeis in Christo nuper regeneratis isti dicunt, a quo magis scandalizabuntur? a me, qui aut illos doceo aut illi me docent [... ]"'. G. de la Concha remite a Rico, op. cit., p. 64, n. 80, que había copiado este pasaje de la Apologia como una de las muchas muestras del trato de Nebrija con judíos y de la colaboración de éstos con los cristianos en las tareas escriturarias. Sin duda hay testimonios de que Nebrija se trataba con judíos, pero todavía no se los ha calificado. Sin espacio para hacerlo aquí, me limitaré a señalar dos puntos para no aceptar su influencia intelectual en $\mathrm{Ne}-$ brija: 1) el papel de los hebreos es siempre auxiliar: dan respuesta a consultas sobre temas de lengua o de realia de la Biblia; 2) con típica mentalidad humanística, las autoridades de Nebrija en materia bíblica siempre son los antiguos: la Septuaginta y especialmente San Jerónimo dentro de los Padres de la Iglesia.

${ }^{4}$ Liber interpretationis 'hebraicorum nominum, en Corpus Christianorum, s. lat., t. 72 , p. 71 . 
bitur, illi qui erant ex tribu Ephraim in verbo Sibboleth interrogati reddebant, hoc est, per sama, non valentes etiam per fidicula et tormenta in hebraici vocem exprimere. Dic Sibboleth, inquit Scriptura, quod in terpretatur 'spica' et respondebant siboleth, sed illud prius per sin, hoc posterius per sama, quam differentiam Graeci et Latini neque litteris neque voce possunt distinguere ${ }^{5}$. quod utrumque vocem possumus efferre: illi vero inemendabili oris pravitate non possunt, illis similes qui erant ex tribu Ephraim, et occupantibus Galaaditis vada Iordanis, cum se vellent ad suos recipere, interrogati dic siboleth, hoc est, per sama, respondebant siboleth per $\sin ^{6}$

${ }^{5}$ De vi ac potestate litterarum, Salamanca, 1503, cap. XVII; en la reciente edición de Antonio Quilis y Pilar Usábel, Sociedad General Española de Librerías, Madrid, 1987; el trozo está en las pp. 66 y 165. Cita el pasaje ALonso, "Nebrija", p. 60, n. 153.

${ }^{6}$ De litteris Hebraicis, Alcalá? Salamanca?, 1507. Este lugar y fecha de impresión son los que le da Alonso, "Nebrija", p. 2. La verdad es que el único ejemplar de la obra que poseemos es de ca. 1515; cf. A. Odriozola, "La caracola del bibliófilo nebrisense", Revista de bibliografía nacional, 7 (1946), p. 38 y F. J. Norton, Descriptive catalogue of printing in Spain and Portugal, 1501-1520, Cambridge University Press, Cambridge, 1978, núm. 38, p. 19a. Alonso no indica en qué se funda para darle el año 1507 a esta obra. No me extrañaría que se basara en I. González -Llubera, quien en la "Introducción" a su edición de la Gramática castellana, Humphrey Milford-Oxford University Press, London, 1926, p. xxxiv y n. 101, razona que ésa debió ser su fecha. Pero la interpretación de González-Llubera no se sostiene. Se basa en dos puntos: 1) en la Apologia, f. b 2 v ${ }^{\circ}$, Nebrija escribe a Cisneros: "Sed cum anno superiori Salmanticae interpretandum recitarem amplitudini tuae quosdam in Sacrae Scripturae locos annotationes meas [...]"'. Esta escena debe referirse al tiempo en que Fernando y la corte estuvieron en Salamanca, de octubre de 1505 a marzo de 1506 (cf. Bataillon, op. cit., p. 29, n. 33). Pero: a) hay un error fatal en la cita: el texto de la Apologia no dice interpretandum sino interpranden$d u m$, y esto hace descartar que Cisneros haya escuchado una Repetitio, que ciertamente no se hacían durante las comidas, sino en un acto público y $b$ ) se ubica al final del año académico, y Cisneros se había ido de Salamanca en marzo; c) la Apologia es de 1507 (cf. Odriozola, art. cit., p. 37), de modo que la expresión "anno superiori" hace remontar la escena a 1506. 2) González-Llubera se funda también en la epístola de Nebrija a Cisneros, probablemente de 1514, en que aquél le dice al Cardenal que "quise traerle a la memoria lo que sobre esto dixele en Salamanca; i le demonstre lo que avia escrito en una Repeticion mia, que hice el año de nuestro Salvador de mil i quinientos i siete años" ( $R A B M, 8,1903$, p. 493). El obstáculo para identificar a De litt. Hebr. con esta Repetitio de 1507 es que su contenido no coincide con el tema por el cual Nebrija escribe a Cisneros, que es el léxico de palabras hebreas, caldeas, árabes y egipcias que se proponía publicar en la Poliglota. Como piensa Bataillon, op. cit., p. 35, n. 49, la Repetitio que mejor corresponde a lo que Nebrija quiere enseñar al Cardenal es la tercera, De peregrinarum dictionum accentu. Y, en efecto, el maestro francés encontró en la biblioteca de la Universidad Complutense de Madrid un ejemplar, dedicado por Nebrija al Cardenal. Este hallazgo no 
Se tiene la impresión que Amado Alonso no supo qué hacer con estos textos. El lamentado filólogo consideraba que la $\zeta$ fue ápicodental africada hasta fines del siglo xvi (y en algunos sitios hasta entrado el siglo siguiente); estaba dispuesto a defender su tesis frente a quienes quisieran hacer de la $\zeta$ una predorsal o una fricativa, pero no se esperaba un testimonio de una $\varsigma$ ceceosa. Se desembarazó de él considerándolo una observación puramente formal: "lo que le importa a Nebrija con este pasaje [se. el de $D e$ litt. Hebr.] no es la pronunciación especial de los ceceosos, sino solamente el hecho de que igualaban la $s$ en la $\varsigma$ (ceceo) en contraste con los franceses que igualaban la $c$ en la $s$ (seseo), sin recoger el importante hecho fonético advertido por [Fr. Pedro de] Alcalá de que esa pronunciación de los ceceosos no correspondía a la $̧$ idiomática del castellano"'7. Pero no es posible librarse tan fácilmente del problema. Es cierto que Nebrija contrapone el proceder de los franceses $(s \sim c>s \sim s)$ con el de los ceceosos $(s \sim \xi>\varsigma \sim \varsigma)$, pero esto lo hace para indicar que la $s$ latina no debe tener el sonido de la $\varsigma$ francesa, sino el de la española. Lo que Nebrija está discutiendo es qué sonido debe tener la s: "s littera quem sonum reddere debeat" ( $D e v i)$, "Fuit tempus quo et putabam tali sono [ $s$ litterae] debere proferri quali nunc imperitum vulgus enuntiat" (De litt. Hebr.).

Por otra parte, al desacreditar el argumento de Nebrija, Alonso se ve llevado a concluir que "menos observador que Alcalá [que había dicho que el tha interdental del árabe no existía en castellano] y más erudito, Nebrija no repara en la diferente articulación de la $̧$ ceceosa, y relaciona el ceceo con la famosa anécdota bíbli-

permitió, sin embargo, cerrar la cuestión, porque el explicit de la Repetitio Tertia es del 30 de junio de 1506. ¿Le habrá fallado la memoria a Nebrija al decir que era de 1507, o se tratará de otra Repetitio? Como se ve, la fecha de De litt. Hebr. todavía está sin precisar; el ejemplar de 1515 bien puede ser reimpresión de una edición de años atrás, pero sobre esto no tenemos pruebas y si se quiere dar a 1507 como año de la edición original, convendría hacerlo añadiendo un signo de interrogación. Por último, hay que señalar que Bataillon, $o p$. cit., p. 35, n. 49 (cf. también p. xc) ha de haber sido inducido a error por una ficha mal tomada cuando escribe que De litt. Hebr. "es una reimpresión de la Repetitio Tertia hecha bajo el cuidado del autor, a causa de que la primera edición se había agotado". No hay tal: se trata de dos trabajos distintos; Nebrija añade después de De litt. Hebr. el texto de la edición agotada de la Repetitio Tertia.

7 “Nebrija", pp. 36-37; también p. 42. 
ca de efraítas y galaaditas, y con su propia idea de la pronunciación grecolatina'" ${ }^{\circ}$. Esta caracterización es inaceptable. Nebrija introduce deliberadamente la comparación con los ceceosos para indicar cuál debía ser el sonido correcto de $s$, ¿cómo vamos a pensar que "no había reparado", si no en la articulación, sí en el sonido que tenía la ç ceceosa? Ciertamente, Nebrija había prestado atención al sonido del ceceo; nos dice que tiempo atrás había creído que era el de aquellas delicias que Quintiliano (Inst. orat., I. xi. 6) prohibía hacer con la $s$. Además, la comparación de la $s$ latina con la $\zeta$ ceceosa no sólo la hace Nebrija en 1503, sino la vuelve a repetir en 1507 (cf. nota 6), en un texto en que ha hecho correcciones y adiciones. Es decir, para sacarse de encima el molesto testimonio de Nebrija, Alonso deja convertido en un atolondrado e ignorante al extraordinario humanista, en contradicción no ya con lo que sabemos de su personalidad, sino con los mismos datos de los pasajes que estudia. Obviamente, la explicación de Alonso está equivocada ${ }^{9}$.

Diego Catalán estima que los ceceosos de que habla Nebrija en $D e v i$ son los sevillanos, que, perdida la africación de la $\varsigma$, la pronunciaban como una predorsal fricativa ${ }^{10}$. No me resulta posible aceptar esta interpretación. Nebrija se refiere a los ceceosos como un "genus quoddam hominum". Ésta no es una caracterización regional; si hubiera estado pensando en los sevillanos, no

${ }^{8}$ Ibid., p. 59.

${ }^{9}$ Hay que tener en cuenta que las "explicaciones" de Alonso no son explicaciones de datos sino apuntalamientos de sus teorías. Si ahora nos dice que Nebrija "no observaba" y se atenía a fuentes librescas, se trata simplemente de argumentos ad hoc para desacreditar textos que iban contra su tesis sobre el sonido de $c$ en el siglo XVI. Cuando Nebrija dice algo que concuerda con sus teorías, Alonso lo pone por los cuernos de la luna. Baste recordar que el desaparecido maestro sentó en Nebrija su extraña tesis de que la $v$ castellana era labiodental, porque a la articulación de ese sonido que da nuestro humanista no puede atribuirse "ni impericia, ni obcecación, ni prejuicio libresco, ni atención insuficiente, ni ambigüedad de expresión" ("Nebrija", p. 67). Sin embargo, la explicación de la $v$ de Nebrija no hace más que reproducir la de Quintiliano, a quien cita (cf. Dámaso Alonso, " $\mathrm{B}=\mathrm{V}$ en la Península Hispánica", en 'La fragmentación lingüistica peninsular, ELH, t. 1, supl., 1962, p. 195). Ahora bien, con respecto a la $v$ es comprensible que Nebrija copie la definición de un tratadista latino, porque quería dar el sonido "verdadero" de la letra, pero en el caso de los ceceosos es obvio que está hablando de sonidos que percibe, porque justamente no se trata de la pronunciación "propia" de una letra.

10 "El çeçeo-zezeo", pp. 323-328. Sobre la tesis de un ceceo que consistiera en pronunciar una $s$ predorsal, cf. la n. 27. 
hay razón para que se hubiera referido a ellos de una manera tan críptica. Decisivo contra la tesis sevillanista es, además, que los ceceosos de Nebrija pronuncian la $s$ como $\xi$ "non sine quadam offensionis levissimae venustate", o sea que cecean como una manifestación de "venustas", no como empleando un rasgo regional. Está hablando Nebrija, pues, según lo indica claramente por otra parte la referencia inicial a las delicias de Quintiliano, de un "cecear por gracia", un tercer tipo de ceceo que debe distinguirse del ceceo como defecto del habla y del ceceo como pronunciación dialectal ${ }^{11}$.

\section{IUD. 12, 6 Y EL SAMEC CECEOSO DE LOS EFRAítAS}

Parece indudable que Nebrija se está refiriendo a un sonido ceceoso. Para entender el hecho, dirijamos nuestra atención al episodio de galaaditas y efraítas (Liber iudicum 12,6) que nuestro autor menciona en ambos pasajes. Al episodio bíblico se refiere como a un paradigma; remitiéndose a él espera que sus lectores comprendan las pronunciaciones de las sibilantes que hacían franceses y ceceosos. Esta cita bíblica, como la previa exposición (tanto de $D e v i$ como en De litt. Hebr.) de los tres tipos de $s$ en hebreo según San Jerónimo, no nos desvían del tema del sonido de $\xi$, como pensó Alonso; al contrario, nos señalan el ámbito dentro del cual se va a mover el pensamiento de nuestro humanista sobre la cuestión. En los autores del Renacimiento podemos rescatar noticias sobre los sonidos de la época o sobre pronunciaciones dialectales, pero tenemos que buscarlas dentro de los temas propios de su momento histórico. No debemos esperar que nos describan un sonido (o que nos hagan trampa a este respecto, copiando la descripción contenida en un libro), como unos fonetistas del siglo XIX, sino que a propósito de un problema de interés en sus tiempos surja una observación sobre sonidos. Si no conocemos ese problema, no podemos valorar esa observación y corremos el peligro de ignorar su significado o de darle un alcance que no le corresponde.

Tratemos de aplicar este principio. Desde fines del siglo $\mathrm{XV}$ Nebrija está metido en los estudios bíblicos; dentro de este cam-

${ }^{11}$ He tratado del "cecear por gracia" en una comunicación leída en el VII Congreso de ALFAL (Santo Domingo, sept. de 1984), cuyas Actas se hallan en prensa. 
po se maneja con las tres lenguas sagradas: hebreo, griego y latín. Nada más natural que una referencia a un episodio proverbial de la Biblia, como era el de Iud. 12, 6. Nebrija ha explicado que la $s$ adquiere su sonido legítimo cuando la pronuncian como $\zeta$ los ceceosos; los pasajes siguientes en que iguala la pronunciación de los ceceosos con el samec de los efraítas le sirven para trasponer el sonido de un defecto del habla (sea de naturaleza, sea empleado como refinamiento cortesano) en un tipo de sibilante propio de una lengua. Sus lectores entendían que se había pasado del plano de la patología del habla al de las "letras de una lengua". Ahora bien, interesa hacer presente aquí que el sonido del samec de los efraítas al que remite Nebrija era dentalizado o interdentalizado. El hacer ceceosos a los efraítas no es una ocurrencia personal de nuestro humanista. En otras versiones o comentarios del pasaje de Iud. 12, 6 se puede encontrar la misma interpretación fonética de esa letra hebrea. Al comprobar que Nebrija está siguiendo una tradición sobre la pronunciación del samec, sus pasajes sobre los ceceosos pierden su extrañeza y se adquiere un punto de referencia sólido para interpretarlos.

La más antigua versión española de Iud. 12, 6, que yo conoz$\mathrm{ca}$, en que se hace interdental al samec de los efraítas pertenece a la General Estoria de Alfonso el Sabio:

Et ellos estando ya alli, vino uno de los de Effraym por passar, e rogo a los de Galaad, que tenien el uado, quel dexassen passar. Et ellos dixieron: "Si non eres de los de Effraym". Dixo les el: "Non so". Ellos nol creyeron, e quisieron lo prouar en el lenguage, e mandaron le que dixiesse $\mathrm{s}$ e b o $1 \mathrm{e} \mathrm{ch}$, que dize en el su lenguage tanto como espiga en el nuestro de Castiella. E non le pudo assi dezir, e dixo $\mathrm{t} \mathrm{h}$ e b o $1 \mathrm{e} \mathrm{ch}$. Et tomaron le e degollaron lo y luego en la passada del Jordan ${ }^{12}$.

Como se ve, Alfonso reproduce el $\sin$ de los galaaditas por $s$, y el samec de los efraítas por th; desde luego, th es la grafía del sonido interdental sordo ${ }^{13}$. En las Biblias francesas de la Edad Media se encuentra la misma reproducción del sin y el samec $^{14}$ :

12 General Estoria, C.S.I.C., Madrid, 1957, t. 2, 1, p. $456 b$.

${ }^{13}$ MARIA BoniOli, La pronuncia del latino nelle scuole dall'antichità al rinascimento, Università di Torino, Torino, 1962, pp. 66-67.

14 Tomo las citas de J. TRÉneL, L'Ancien Testament et la langue française du Moyen Âge, Cerf, Paris, 1904, p. 75. 
Quant lor anemi lor faisoient dire Seboleth, ke signifie espi, quant il ne pooient dire, si disoient tebolet (Bibl. del Arsenal, ms. 2083, f. $57 \mathrm{v}^{\mathrm{o}}$; siglo $\mathrm{XII}$ ).

Il li distrent, di donc Seboleth qui sone autre tant como espi, e il respondi theboleth e ne pot pas nommer espi par cele meismes letre (Bibl. Nationale, ms. 899, f. 119; s. XuI).

Il li distrent or di donc Sepoleth mais cil ne le dist mie ainz dist theboleth (Bibl. Nationale, ms. 15392, f. 89; s. XIII).

Dy doncques ce mot Seboleth qui vault autant à dire comme espi lequel respondi theboleth (Bibl. Nationale, ms. 153, f. 162; s. XIV).

Ilz diront, or dis doncques Sebolech, mais il ne dist, ains dist Theobolech (Jean de Rély, Bible française, Paris, 1544; ms. de 1496).

En el $\S 4$ pueden verse otros ejemplos de considerar $s$ al sin y $[\theta]$ al samec en las glosas de Iud. 12, 6. Este uso se extendió hasta el siglo XVII. Por proceder de un personaje tan destacado y por encontrarse en un pasaje de importancia para la historia fonética del español, es de particular interés que Benito Arias Montano coloque un samec ceceoso en boca de los efraítas en su comentario al Libro de los jueces. Vistas las cosas desde esta perspectiva, la versión de los efraítas ceceosos de Nebrija empieza a revelársenos como un eslabón de una tradición que se extiende desde Alfonso el Sabio en el siglo xiI hasta Arias Montano a fines del siglo xvI, y aun podremos documentarla en España a principios del siglo XVII.

\section{Los efraítas ceceosos de Arias Montano y Aldrete}

El pasaje de Montano es bien conocido desde que Cuervo ${ }^{15}$ lo exhumó de una página de Aldrete. Este gran filólogo del Siglo de Oro había aducido el episodio de galaaditas y efraítas de Iud. 12, 6 para mostrar la existencia de divisiones dialectales en el hebreo,

15 "Disquisiciones sobre antigua ortografía y pronunciación castellanas", $R H i, 2$ (1895), pp. 39-40, n. 21, y en Obras, Instituto Caro y Cuervo, Bogotá, 1954 , t. 2, pp. 279-280, n. 21. En la segunda versión de las "Disquisiciones", Obras, t. 2, p. 435, n. 140, Cuervo reconoció hidalgamente que fue Aldrete quien "descubrió" el pasaje de Montano. 
y a continuación se refirió al "exemplo doméstico" con que Arias Montano explicó el pasaje bíblico, "exemplo" que a su vez él confirma con otro personal suyo de sus años de estudiante en Salamanca ${ }^{16}$. En efecto, al comentar el Libro de los jueces 12, 6, Arias Montano había considerado como vicio la pronunciación de los efraítas y se había extendido sobre la aparición de barbarismos debidos a la incuria o afectación de la gente, según le había enseñado la "experientia etiam diligenter observata" 17 . En el tercero de sus ejemplos se refiere al habla de su ciudad adoptiva y nos cuenta sus famosos recuerdos sobre la confusión de las sibilantes en Sevilla. Para el punto que aquí tratamos, no es necesario discutir el (falso) problema, levantado por Alonso, de las fechas de distinción y confusión que da Montano; partamos simplemente de que nos dice que veinte años después de su niñez varió tanto la pronunciación de los andaluces, y sobre todo de los sevillanos, con respecto a la de las gentes de las dos Castillas, que:

[...] [1] nisi verborum fortasse quorundam discrimen intersit, Hispalensem a Valentino plane non discernas, cum utrisque pro s, $z z$, et contra pro zz siue pro Castellanorum $\zeta$, s usurpatur; [2] ita ut, si a Bethico verbum S I B O L E T H exigatur, nullum aliud quam Ephraitarum Zziboleth, siue siboleth audiatur ${ }^{18}$.

Amado Alonso basó su interpretación de este pasaje en la grafía $z z$ del samec: "Escribiendo en latín y en una época en que $\zeta$ se interpretaba umversalmente como $d s$, con la doble $z z$ inicial sin duda quería expresar una mayor energía articulatoria, en este caso la fortis ts por la lenis $d s$. Pues bien, por dos veces iguala esa $z z$ con la $\zeta$ de los castellanos"'19. No nos dejemos engañar por la forma en que está escrito este párrafo. No se trata de que la grafía $z z$, representativa de $t s$, venga a igualarse con $\zeta$ y así se revele que el sonido castellano era "algo como $t s$, que correspondía aún a

16 Varias antigüedades de España, África y otras provincias, Amberes, 1614, p. 152

${ }^{17}$ De varia Republica, sive Commentaria in librum Judicum, Antuerpiae, ex officina Plantiniana, 1592, p. 494. Agradezco al Prof: José Polo, de la Universidad Autónoma de Madrid, el haberme procurado fotocopia del comentario al cap. 12, 6 .

${ }^{18} \mathrm{Op}$. cit., p. 495. Desde luego, soy yo quien ha introducido los números.

${ }^{19}$ De la pronunciación medieval a la moderna en español, $2^{\mathrm{a}}$ ed., Gredos, Madrid, 1967, t. 1, p. 255. Citaré en adelante a los dos tomos de esta obra como Pronunciación. 
la pronunciación española de base toledana" 20 ; lo que ocurre es que Alonso se está imaginando por qué Montano escribe con $z z$ un sonido que indiscutiblemente debía ser africado puesto que se lo igualaba con la $\varsigma$, que para el llorado filólogo mantuvo este modo de articulación hasta entrado el siglo xvir. No es, pues, que la $z z$ represente a $t s$, sino que, por creer que la $c$ era $t s$, se interpreta que la grafía $z z$ (que se iguala a $\varsigma$ ) ha de tener el valor de $t s^{21}$. El argumento de Alonso es de todo punto insostenible; ha debido ignorar que $z z$ es para Montano la grafía del samec ¿y cómo va a ser africado el samec? Tampoco la $\zeta$ "se interpretaba universalmente como $d s$ ". En la nota de Robert Estienne sobre la pronunciación de galaaditas y efraítas que copio en el $\S 6$, la pronunciación con el samec, que suena "ut $s$ nostrum inter duas vocales in medio dictionis", se escribe ziboleth; cf. también la nota 24.

Pero lo que resulta más alarmante es que Alonso haya empleado la imaginación para un problema que debía ser resuelto por una investigación. Con sólo acudir a los textos de Montano, comprobamos la inanidad de suponer que al escribir $z z$ " $\sin \mathrm{du}$ da quería expresar una mayor energía articulatoria'; en efecto, el gran hebraísta representa el zain hebreo (una fricativa sonora) con la $z: \Omega \ldots$ ZE RETH ${ }^{22}$. Es obvio que con la reduplicación de $z$ no ha podido estar pensando en crear un símbolo de $t s$. Además, no presenta como una invención suya la representación del samec por $z z$ :

\section{IZZAR רִ הִ ASSARION, ASSIS}

Graece legimus $\dot{\alpha} \sigma \sigma \alpha \varrho i o \nu$ eadem fere voce cum IZZAR, cum D littera aliis per duplex ss, aliis per $z z$ pronunciatur, dum ad aliarum linguarum scripturam refertur ${ }^{23}$.

“Aliis per zz”: el plural es bien significativo.

${ }^{20}$ Ibid., p. 255.

${ }^{21}$ Alonso cuenta en adelante el testimonio de Montano como una prueba más de que $\zeta$ era africada; cf. Pronunciación, pp. 305, 314. Así se crea un perfecto círculo vicioso: la idea previa de que $\zeta$ era africada hace interpretar a la $\varsigma$ de Montano como africada, $y$, a su vez, la $\varsigma$ de Montano confirma la idea de que la $\zeta$ de fines del siglo Xvi era aún africada. A éste y otros tipos de explicaciones de Alonso me refiero en mi estudio "La tesis de una $\varsigma$ africada entre 1580-1630', ALHis (en prensa).

${ }^{22}$ Thubal-Cain, sive de mensuris sacris liber, f. 6a, en el t. 8 de la Biblia Regia de Amberes, 1572 .

${ }^{23}$ Ibid., f. 18a. 
Si examinamos la manera como Montano transcribe las letras hebreas, observamos lo siguiente: la $s$ está reservada al sin; el samec, pues, no era [s] y para representarlo había que echar mano de la otra letra de una sibilante no palatal, o sea, la $z$. Pero ésta era usada tradicionalmente como equivalencia del zain $^{24}$, con el que correspondía bien debido a la pronunciación fricativa de la $\zeta$ del griego moderno. La forma doble puede representar una solución a este problema de tener ya ocupada la letra $z$ para el zain; la única manera de poder utilizarla para el samec era hacerlo con una forma que se distinguiera de la empleada para el zain. Esto es simplemente un examen de las posibilidades ortográficas con que contaba Montano -o la tradición en que se inscribe- para representar el samec. Creo que es en el terreno de la ortografía donde hay que plantear la cuestión; Alonso imaginó que la duplicación de la letra significaba un aumento de la energía articulatoria de $z(=d s)$, pero esta explicación no sólo contradice los hechos, sino interpreta equivocadamente la grafía $z z$ como si se tratara de la transcripción fonética de un sonido; este proceder constituye un anacronismo inaceptable que no puede hacer más que crear la confusión en un problema de suyo ya difícil. Los tratadistas del Siglo de Oro se manejan con letras; Alonso, desgraciadamente, los consideraba como fonetistas que estaban "describiendo sonidos" con mayor o menor perfección.

Del grafema $z z$ de Montano lo único seguro que se puede decir es que representa una sibilante que no era $s$ : ni la sorda ( $\sin$ ), ni la sonora (zain). Cuál fuera ese sonido, por este dato no lo podemos averiguar, pero tenemos otra pista para hacerlo: el pasaje del comentario al Libro de los jueces en que nuestro escriturario iguala el samec de los efraítas a "la $\&$ de los castellanos". En este punto hay que invertir el método de Alonso y en vez de querer determinar lo familiar (el sonido de la $\varsigma$ ) por lo remoto y oscuro (la $z z$ del samec de Montano), partamos de lo próximo y atestiguado con seguridad para averiguar lo lejano e insuficientemente aclarado. Montano nos informa que veinte años después de su niñez no se podía reconocer a un sevillano de un valenciano, porque ambos pronunciaban $z z$ por $s$, y $s$ por $z z$, $c$. Ésta es una de las tantas referencias a lo que Alonso llamaba el "trueque anárquico" de las

${ }^{24}$ Cf. los textos de Corro (Alonso, Pronunciación, 1, 236) y de Teodoro de Beza (ibid., 236, n. 189). También cuando el Brocense (ibid., 2, 208, n. 60) advierte que $z$ procede del tsade y no del zain y censura la pronunciación como de $s$ o ss entre vocales, está denunciando la existencia generalizada de una forma fricativa. 
sibilantes $\zeta^{-s^{25}}$, pero que, en realidad, no es otra cosa que la situación de errores y ultracorrecciones que se da cuando unos hablantes deben practicar cierta distinción fonológica de la lengua general que falta en su habla regional ${ }^{26}$. Lo que Montano está testimoniando es, pues, el ceceo sevillano, como se desprende de sus mismas palabras tras la referencia al "trueque anárquico": "ita vt, si a Bethico verbum S I B O L E T H exigatur, nullum aliud quam Ephraitarum Zziboleth, siue çiboleth audiatur", Los andaluces pronunciaban $\xi$ por $s$ : "nullum aliud audiatur" de ellos. $¿$ ¿Vamos a pensar que pronunciaban la $̧$ africada que les adjudicó Alonso, con lo que su ceceo vendría a ser un sorprendente tsetseo? Por supuesto que no. Si los andaluces ceceaban, la $\xi$ que articulaban debía ser interdentalizada, porque el ceceo supone por fuerza una pronunciación de este género ${ }^{27}$. Por lo tanto, cuando Montano nos dice que de los andaluces no se escucha otra cosa

${ }^{25}$ Pronunciación, t. 2, p. 105.

${ }^{26}$ Cf. Álvaro Galmés de Fuentes, Las sibilantes en la Romania, Gredos, Madrid, 1962, p. 79, y mis Siete estudios sobre el español dé América, UNAM, México, 1983, pp. 81-84.

${ }^{27}$ Eminentes estudiosos han considerado que la palabra cecear también significó en el Siglo de Oro la pronunciación de una $\varsigma$ predorsal fricativa (en algunos autores, con un timbre que alternaba entre siseo y ciceo); cf. Diego Ca. TALÁN, "El çeçeo-zezeo", p. 309; RaFaEL LAPESA, "Sobre el ceceo y el seseo andaluces", $H A M$, reproducido en sus Estudios de historia lingüistica española, $\mathrm{Pa}$ raninfo, Madrid, 1984, pp. 263-264; A. GALMÉs, Las sibilantes en la Romania, p. 80; Manuel Alvar, "A vueltas con el seseo y el ceceo", Rom, 5 (1972), pp. 44, 50; JosÉ MONDÉJAR, "Disquisiciones históricocríticas y metodológicas sobre la interpretación de los datos en el estudio del șeșeo", $R L i R, 49$ (1985), pp. 271-272 y 284-286; y PaUl M. LloYd, From Latin to Spanish, American Philosophical Society, Philadelphia, PA, 1987, p. 337. Por mi parte, mis lecturas y reflexiones me han llevado a mantenerme en la posición tradicional y no me resulta posible aceptar que el verbo cecear haya podido tener alguna vez el significado de [sesear]. Si Dios lo permite, expondré en algún próximo estudio mis razones. Entre tanto, para no dejar sin algún fundamento la conclusión que saco en el texto, basada en que cecear significaba una pronunciación dentalizada o interdentalizada, observaré lo siguiente. Creo que se estará de acuerdo en que Montano documenta el ceceo sevillano. Si esto es así, la $\zeta$ de que habla no puede ser predorsal, porque en este caso no habría podido decir que los sevillanos pronuncian $\varsigma$ por $s$. Según es bien sabido, los españoles no distinguían la $s$ predorsal y la $s$ apical como fonemas distintos; así, por ejemplo, Montano nos cuenta que las francesas sustituían $r$ por $s$, es decir, por la $s$ predorsal, que él llama simplemente $s$ (cf. De varia Republica, p. 494). En consecuencia, si la ç hubiera sido [s] para Montano, los sevillanos no se hubieran diferenciado de los valencianos, que pronunciaban $\zeta$ como $s$. Como nos dice que reducían $\xi^{-s}$ a $\zeta$, el sonido de ésta tenía que ser otra cosa que $s$. 
"quam Ephraitarum Zziboleth, siue çiboleth", la equiparación de la $z z$ de los efraítas con la "Castellanorum $\xi$ " quiere decir que con la grafía $z z$ estaba representando un sonido interdentalizado. No puede haber vuelta de hoja: los efraítas eran ceceosos para Montano.

También lo eran para su comentador Aldrete. A fin de ilustrar las diferencias dialectales entre las lenguas semitas, realiza algo así como una versión ampliada del episodio de Iud. 12, 6 y pasa revista a las variedades de pronunciación de la palabra espiga (siboleth) en hebreo, caldeo, sirio y árabe. Después de haberlo hecho, observa en el margen:

La espiga en Arabe çubula, i çubul, pronunciaron los Arabes como los Ephraitas, i no como los Galaaditas ${ }^{28}$.

Se ve que, como Montano y Nebrija, Aldrete hace equivaler a $\varsigma$ la sibilante de los efraítas, por él igualada a la del árabe. Podemos estar seguros de que esa $\zeta$ de efraítas y árabes representaba una sibilante ceceosa para Aldrete. Tratando de la etimología de la palabra Tiro indica su origen en la raíz sor 'peña, piedra, roca'. Traza luego el cuadro de su desarrollo en las diversas lenguas semitas y escribe a propósito del árabe:

A la piedra llamo el Arabe Taur, i al peñon grande çahra. la roca, peña en la mar çahara, i los roquedos tambien, pero al risco haffa. Desto se conoce bien el nombre de Sor, que el Arabe dixo Sar, pero ceceando, $\varsigma a r^{*}$, que lo vsan en su lengua de ordinario. i assi sarha ${ }^{29}$.

La nota a la que remite el asterisco de la palabra ceceada çar dice:

Angelus Caninius in dialector. Canonib. in $\theta$ optimè in sua lingua Poenos, intellige Arabe[s] Africanos, balbutire asserit ${ }^{30}$.

El testimonio es tan claro que se hace innecesaria una discusión: el sonido con que cecean los árabes africanos está presentado con una $\theta$. Éste era el sonido que pronunciaban los árabes como los efraítas.

28 Antigüedades, p. 154.

29 Ibid., p. 239.

${ }^{30} I d$. 


\section{El SAMEC CECEOSO EN HEBREO}

Pero, se dirá, ¿cómo va a ser el samec un sonido ceceoso? Para negarse a aceptar que fuera ceceosa la $\xi$ española que Nebrija igualaba al samec, Amado Alonso afirmaba que "nunca se ha atribuido al samech tal cualidad [ciceante]"31. La verdad es que, según se acaba de ver, no faltan testimonios de que el samec tuviera un sonido ceceoso. Esto no ocurre sólo en las versiones romances de la Biblia. Dos hebraístas de la talla de Arias Montano y Aldrete lo hacen corresponder con sonidos dentalizados o interdentales, y ya esto nos hace sospechar que también entre los hebreos se le atribuiría esta articulación. Efectivamente, como los cristianos en sus versiones de Iud. 12, 6, también los hebreos tuvieron su tradición medieval del samec ceceoso y parece razonable suponer que, al constituirse el hebraísmo cristiano a principios de la época moderna, haya sido este tipo de samec el que aprendieron de sus maestros hebreos los estudiosos que hacen bleso al sonido de esta letra. Paso revista a continuación a estos testimonios.

Dos de las grandes figuras de la erudición bíblica y gramática hebrea de la Edad Media nos proporcionan los primeros ejemplos. El rabino Salomón Isaaki (1030-1105), más conocido como "Rashi', glosando Iud. 12, 6 escribe:

Ephraitae non poterant dicere schibboleth, quia balbutiebant lingua sua. $D$ I I balbutit: $D$ I I $D$ qui non potest pulchre, sive recte, proferre verba sua, balbus, $\psi \epsilon \lambda \lambda$ ós. ties, blaesa pronunciatio vocum ${ }^{32}$.

Para Rashi, pues, el samec de los efraítas tenía una "blaesa pronunciatio"'. Lo mismo declara David Quimhi (1160?-1235?) en su comentario al Libro de los jueces:

The Ephraimites used to pronounce $\because \cdots, \cup$ as $\because \cdots D$, as they were lisping ( $i$ ○ D ). Possibly they were influenced in this by the climate of their country, as are the French (Jews), who are not able to pronounce $r \cdot \boldsymbol{U}$, but sound it like fricative $\Omega^{33}$.

31 "Nebrija", p. 37; también Pronunciación, t. 1, p. 255.

32 Tomo el pasaje de Drusius (Jean van Der Driesche), Annotata ad Librum iudicum, en Critici Sacri, Frankfurt, 1696, t. 1, col. 2061. La transcripción de $ש$ por sch se deberá a Drusius, lo mismo - pienso- que las equivalencias con el latín y el griego.

${ }^{33}$ Sin querer hacer una segunda traducción al español, tomo la cita de 
Quimhi no puede expresarse con mayor claridad sobre el carácter ceceoso del samec; para que no quede la menor duda sobre el sonido, dice al final que es como el del tau raphatum, o sea [ $\theta$ ].

En la primera mitad del siglo xiv, el más famoso exégeta cristiano de la Biblia en la tardía Edad Media, Nicolás de Lyra (12701349), también va a explicar como ceceoso al samec de los efraítas:

[...] unde secundum hebreos sic dicebant eis: dic seboleth fluvium transibo. Qui rendebant cheboleth, ad cui intellectum sciendum quod apud hebreos litera $s$ triplicatur. Vna vocant sin et habet fortem sonum ubicumque ponat in principio, medio vel fine dictionis sicut nostra $s$ cum ponitur in principio dictionis vel fine. Alia vocatur samech et habet talem cum pronunciatur ab homine liguam blesam habente, et sonus eius appropinquat ad sonum literae que apud nos sonat $c$, per qua litera in latino ponitur $c h$. Unde adhuc in antiquiis abbatiis, que sequuntur modum pronunciandi antiquum [sic] pronunciant Macheus, ubi scribitur Matheus; illi autem de Ephraim vel per corruptione ligue vel per consuetudinem, per litera sin pronunciabant literam samec sicut homo blesus, per hoc nomine Simon diceret Chimon $^{34}$.

Observemos que Lyra está explicando Iud. 12, 6 según lo que le contaron los judíos o leyó en sus obras: "secundum hebreos"; no sería difícil, pues, que su idea de la pronunciación ceceosa de los efraítas proviniera de Rashi o de sus discípulos, fuente muy utilizada por el franciscano francés. Sus noticias sobre el samec propiamente dicho no son fáciles de interpretar. Sienta la equivalencia entre el samec, que es una $s$ pronunciada por alguien "li[n]guam blesam habente", y el "sonum qui apud nos sonat $c$ ". Acaso la clave de esta correspondencia se encuentre en que Lyra tenía la costumbre de explicar los términos hebreos, traducidos al latín, por palabras de su dialecto normando ${ }^{35}$, y bien pudiera ocurrir que la igualdad entre el samec y la $c$ "apud nos" fuera una extensión de esta práctica al terreno fonético. En normando $c^{\ell, i}$ se ha conservado como $s^{36} \mathrm{y}$, de ser acertada mi interpretación, pronun-

la versión inglesa que da IRENE GARBELl, "The pronunciation of Hebrew in Medieval Spain', Homenaje a Millás Vallicrosa, C.S.I.C., Barcelona, 1954, t. 1, p. 666; 'megamgemin' es propiamente 'balbuciendo': '

${ }^{34}$ Biblia latina cum postillis Nicolai de Lyra, (Bonetus Locatellus) impensis Octaviani Scoti, Venetiis, 1489, t. 1, Liber Iudicum, f. 4 ro

35 HERMAN HAILPERIN, Rashi and the christian scholars, University of Pittsburgh Press, Pittsburgh, PA, 1963, Pp. 137, 282.

36 A. Galmés, Las sibilantes en la Romania, p. 155. 
ciar la $s$ con la lengua blesa significaría para Lyra palatalizar el sonido, no interdentalizarlo (se trataría del "sigmatismo palatal", una conocida variedad del ceceo). Esta interpretación tropieza con el siguiente obstáculo: a la equivalencia de sonidos entre el samec y la $c$ normanda (?), Lyra añade que por esta segunda letra "in latino ponitur $c h$ "; desde luego, la grafía $c h$ corresponde a una sibilante palatal en francés, no en latín. En esta lengua valía por [k]. Sin embargo, me parece lo más probable que haya algún significado de la palabra latino que ignore, o tal vez se me escapen valores del dígrafo $c h$, porque lo cierto es que los ejemplos que da Lyra sólo pueden comprenderse suponiendo que $c h$ sonaba $\stackrel{v}{s}$ para él. En la forma Macheus por Matheus podría tratarse de la palatalización de $t$ por lo que ya debería ser una yod siguiente, pero en el ejemplo de Chimon por Simon es seguro que ch no está representando a [k] como en latín: es imposible pensar que Lyra está dando a [kimón] como pronunciación con lengua blesa de Simón. En el texto de la Biblia en que están las Postillae de Lyra figura cheboleth en boca de los efraítas. Esta forma con ch no se encuentra en ningún manuscrito latino de la Biblia (cf. § 5) y bien podría ser una "corrección" que Lyra hubiera hecho en el texto de la Vulgata (a esta forma se refiere Pagnini; cf. § 6). Es sabido que, preludiando el tema de la época siguiente, al franciscano ya le parecía que había que corregir los manuscritos latinos de la Biblia según el texto hebreo ${ }^{37}$.

Stephan Bodeker (1384-1459), obispo de Brandenburgo, en su tratado Adversus Judaeos tiene una sección inicial sobre la pronunciación del hebreo, que, por supuesto, es la de los judíos a los que ha recurrido para aprender la lengua ${ }^{38}$; tras citar el pasaje de San Jerónimo, Lib. nom. Hebr., sobre las tres clases de $s$ en hebreo, el obispo lo comenta de esta manera:

Samech vero contracto inferiori labio quasi per dentes fertur ad modum blesorum, qui apud latinos non debite sciunt proferre $s$ quasi quoddam medium inter literam $c$ et literam $s$; et inde est, quod omnes fere iudei blese loquuntur, quod volgus false estimat ob circumscisionem ligwe fieri. Tamen circumcisio non in ligwa sed in prepucio fieri conswueuit. Tante eciam difficultatis videtur differencia proferendi inter sin et samech, quod plures eciam originaliter nati iudei

${ }^{37}$ Cf. Biblia latina cum postillis Nicolai de Lyra, "Prologus", t. 1, f. a $2 \mathrm{v}^{\circ}$ a-b.

38 Bernhard Walde, Christliche Hebraisten Deutschlands am Ausgang des Mittelalters (Alttestamentliche Abhandlungen, t. 6, partes 2-3), Münster, 1916, pp. 31-32. 
sin pro samech proferunt uel e conuerso, sicut multi latini et maxime stangnales nullam faciunt differenciam inter $c$ et $s$. Unde dicunt defisit pro deficit, in prinsipio pro in principio. Et predictus videtur facere, quod habetur iudicum XII: die ergo sebalech sabalech, qui respondebit: cebalech. in hebreo Primum est scriptum per literam syn, Secundum vero per literam samech ${ }^{39}$.

De las muchas noticias que da Bodeker, destaquemos las que interesan para este trabajo: el samec se pronuncia "ad modum blesorum', de lo cual resulta que "omnes fere iudei blese loquuntur'. Y, como dice al final del trozo, esta pronunciación blesa del samec era la de los efraítas en los vados del Jordán.

A mediados del siglo XvI el hebraísta suizo Johann Forster (1496-1558) todavía ofrece un ejemplo de samec ceceoso: "

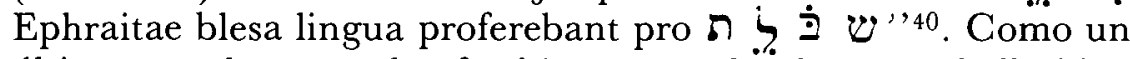
último eco de este valor fonético otorgado al samec, hallo bien entrado el siglo xviI que un comentarista inglés de la Biblia se duele de que a un efraíta le costara la cabeza no poder pronunciar el siboleth con sin, "seeing an innocent that had the infirmity of lisping or stuttering so have punished" 41 .

\section{El siboleth de la Vulgata medieval}

Hasta ahora he venido exponiendo los datos sobre la interpretación del siboleth y sobre la pronunciación hebrea del samec en la Edad Media; llega el momento de empezar a discurrir sobre estas noticias. El origen de la pronunciación ceceosa que en las Biblias cristianas se atribuye a los efraítas puede trazarse con seguridad: corresponde a la tradición de la Vulgata latina. El más antiguo testimonio español que he podido aducir, el pasaje de la General Estoria sobre Iud. 12, 6 (cf. $\S 2$ ), es una traducción de la Biblia, como era de esperar. Alfonso ha utilizado para su versión la difundida Biblia de la Universidad de París, o sea el llamado ms. Universitatis o Sorbonicus (Parisinus lat. 15467, s. XIII). No puede caber duda de esto, porque las formas sebolech y thebolech de la $E s^{-}$

${ }^{39}$ Ibid., p. 56.

${ }^{40}$ Dictionarium Hebraicum novum, Basilea, Froben, 1563. Entiendo que hay una primera edición de 1557 (cf. RAPHAEL LOEWE, "Christian hebraists", Encyclopedia Judaica, t. 8, col. 31).

41 Annotationes upon the Books of the Old and New Testament [... ], Evan Tyler, London, 1657, f. li $1 \mathrm{v}^{\circ} \mathrm{b}$. 
toria alfonsí únicamente aparecen en el manuscrito de la Universidad de París ${ }^{42}$. Asimismo de la Vulgata proceden las formas del siboleth de las Biblias francesas. Ya que el conocimiento que se tuvo del episodio de galaaditas y efraítas proviene de la Vulgata, conviene ver cómo se representaba en los manuscritos la diversa pronunciación de una y otra tribu. En cuanto a los galaaditas, la casi totalidad de los manuscritos les da la forma sebboleth, con pequeñas desviaciones de reducir $-b b-\mathrm{a}-b-$, o $-t h$ a $-t$; sólo en tres códices muy antiguos y en el de la Universidad el sonido final aparece como $c h$.

Para los efraítas, las formas que dominan son tebboleth y thebboleth, también con variaciones menores: $-b b->-b-\mathrm{y}-t h>-t$. Pero diez códices tienen Gebboleth-iebboleth (dos de ellos como correcciones de una segunda mano); también debidas a una mano posterior aparecen en tres códices sebboleth, zibboleth, sepolith. Estas enmiendas muy probablemente han de deberse al cambio de interpretación fonética del sin y el samec de que hablo en el parágrafo siguiente, pero, de cualquier manera, el uso de una segunda letra y tantas correcciones muestran que la pronunciación de los efraítas planteaba problemas que no presentaba la de sus adversarios. Con todo, $t \mathrm{y}$ th son las representaciones ampliamente preferidas y la edición crítica de la Vulgata da a la primera como la forma original.

Estas grafías del sin y el samec se deben a San Jerónimo. La Septuaginta no había intentado reproducir las diferencias de pronunciación entre galaaditas y efraítas. El "codex Alexandrinus", sustituye al siboleth por $\sigma v \dot{\nu} \theta \eta \mu \alpha$ 'contraseña' y el "codex Vatica-

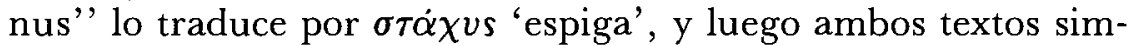
plemente decían que los efraítas "no lo pudieron pronunciar así". De las antiguas traducciones latinas de la Biblia no se conservan fragmentos correspondientes a Iud. 12, 6, pero dado que solían depender de la versión griega, es probable que hubieran tratado del mismo modo el problema de la traducción del siboleth. San Jerónimo se abocó a la cuestión con su talento de artista; no hizo una traducción de la palabra, en que se perdían las connotaciones bíblicas de la historia, sino una transcripción de las dos formas del vocablo hebreo, manteniendo así con una diferencia de

${ }^{42}$ Biblia Sacra, iuxta latinam Vulgatam versionem, ed. de los PP. Benedictinos de la Abadía de San Jerónimo de Roma, Typis polyglottis Vaticanis, Romae, 1939 , t. 4 , segundo aparato crítico, p. 303b. La variantes del siboleth que citaré en el texto proceden de esta edición crítica de la Vulgata. 
sonidos el dramático realismo del texto original. El santo transcribía las tres sibilantes hebreas con la $s$ latina o la sigma griega; para Iud. 12, 6, en que quiso distinguir entre el $\sin$ y el samec, creó las formas sebboleth tebboleth. Ahora bien, con esta representación estableció entre el sin y el samec una oposición de siseante ceceante: [s]-[s, $\theta]$. San Jerónimo, pues, introdujo una caracterización fonética de esas dos sibilantes diversa de la fijada en la masora, la escritura canónica hebrea; en ésta, el sin y el samec se oponen como chicheante siseante: $s^{s}-s$. Está oscuro por qué San Jerónimo da una oposición distinta de la registrada en la masora; se ha pensado alguna vez que escuchaba una variedad regional del hebreo distinta de la que sirvió de base a la sistematización de la masora. Sea de esto lo que fuere, lo cierto es que por medio de la Vulgata el valor ortográfico-fonético que San Jerónimo dio al sin y al samec dominó en toda la Edad Media e inclusive perduró hasta finales del siglo xvi. Aparece en la Biblia Poliglota Complutense del Cardenal Cisneros ${ }^{43}$, en la Biblia publicada por Gobelino Laridio ${ }^{44}$, en la Biblia Regia de Amberes que dirigió Arias Montano ${ }^{45}$ y todavía se encuentra en el texto del Libro de los jueces que este famoso escriturario sevillano comentó hacia el fin de su vida ${ }^{46}$.

Sin embargo, en el siglo xvi la interpretación fonética de San Jerónimo había entrado en una crisis definitiva y al término de la centuria se impusieron, tanto en el mundo protestante como en la Iglesia Católica, las formas $s c h, s h$, se para el $\sin$ y $s$ para el samec; esto es, se cambió la oposición siseante $\sim$ ceceante de la Vulgata medieval por la chicheante siseante de la masora (y probablemente ya mayoritaria entre las comunidades hebreas).

\section{El CAMBIo de VALORES FONÉTICOS EN LA ÉPOCA MODERNA}

Desde principios del siglo xvi es manifiesta la tendencia a abandonar la versión jeronimiana del siboleth. La oposición $s$-th se en-

${ }^{43}$ Biblia sacra, hebraice, chaldaice et graece, cum tribus interpretationibus latinis: de mandato ac sumptibus Cardinalis D. F: Francisci Ximenez de Cisneros, Arnao Guillén de Brocar, Alcalá, 1514, t. 2, f. $g$ iiii vo .

${ }^{44}$ Biblia iuxta divi Hieronymi Stridonensis traslationem [...], Colonia ex officina Eucherij Cervicorni, 1530; cf. Biblia Sacra, iuxta latinam Vulgatam versionem, t. 4, pp. 303-304, segundo aparato crítico.

45 Biblia sacra hebraice, chaldaice, graece et latine, Philippi II. Regis Catholici pietate et studio ad sacrosanctae Ecclesiae usum, cura et studio Benedicti Ariae Montani, Antuerpiae, Christoph. Plantinus excud., 1569, t. 2, f. 172.

${ }^{46}$ De varia Republica, citada en la nota 17, p. 493. 
cuentra reemplazada por otra distinta en las ediciones de la $\mathrm{Bi}$ blia de Robert Estienne, tan importantes por la influencia que ejercieron ${ }^{47}$. Su texto fue adoptado por las ediciones de Lovaina de 1547 y 1583, la última de las cuales sirvió de base a la comisión papal que determinó el texto considerado como auténtico por la Iglesia. Ahora bien, Estienne, desde la primera edición de 1528 hasta la cuarta de 1545 (que es la última que he podido consultar), transcribe la pronunciación de galaaditas y efraítas como schibboleth sibboleth. Contra lo que podría creerse a primera vista, estas grafías no representan una oposición $s$ s-s. En una nota de la cuarta edición de la Biblia, Estienne aclaró los valores que da al siboleth de Iud. 12,6:

Haec vox Hebraea cum $ש$ et puncto dextro scribitur apud Hebraeos, cum sonat vt nostrum $\mathrm{s}$ in principio dictionis [...] ש vero cum puncto sinistro profertur vt s nostrum inter duas vocales in medio dictionis, vt musa. Haec vox Hebraea per $D$ samech scribitur, quod quidem samech proferebatur, vt $\boldsymbol{W}$ cum puncto sinistro, hoc est vt $\mathrm{s}$ nostrum inter duas vocales in medio dictionis, quasi pronuntiares ziboleth, quum fuisset pronuntiandum siboleth, vt solemus nostrum $s$ in principio dictionis ${ }^{48}$.

Así, para Estienne la oposición entre el sin y el samech es de sonoridad entre sibilantes dorsales: [s] - [z]. Las notas de la cuarta edición de la Biblia de Estienne proceden, como es sabido, de apuntes tomados en las clases de Vatablo (o, mejor dicho, como tales fueron presentadas por Estienne); no parece caber duda, sin embargo, de que representan las ideas de Estienne sobre esos sonidos hebreos, no sólo por lo improbable (aunque no imposible: no se conoce bien la historia de las notas de Estienne) de que introdujera una anotación con la que no estaba de acuerdo, sino porque en cierta ocasión se refirió él mismo a los valores fonéticos del sin y el samec de una manera análoga a la de Vatablo. He aquí el pasaje:

Nostrates auinionensium Iudaeorum pronuntiationem sequen-

47 Para la historia de las ediciones latinas del texto bíblico en el siglo XVI, cf. Dom Henri Quentin, Mémoire sur l'établissement du texte de la Vulgate, RomaParis, 1922, pp. 95-208 (citado en adelante: Mémoire). f. $148 \mathrm{v}^{\circ}$.

${ }^{48}$ Biblia, Lutetiae, ex officina Roberti Stephani, typographi Regii, 1545, 
tes, cum habet in dextera parte punctum, leniori et molliori sibilo proferunt, quod si in sinistra, paulo vehementiori ${ }^{49}$.

Esta referencia a los judíos de Aviñón la podemos controlar. En el judeo-provenzal el sin es predorsal y el samec se interdentalizó, pasando más tarde a $f^{50}$. El sin de Estienne, pues, indudablemente era $s$; lo que me resulta inexplicable es la oposición de sonoridad que establece con el samec, oposición de cuya existencia no tengo noticia. A pesar de la oscuridad de este punto, queda en firme una consecuencia de importancia: Estienne da al sin y al samec del siboleth unos sonidos diferentes de los tradicionales.

Y no sólo sonidos, sino también grafías. Es singular la de sch para representar el $\sin [\mathrm{s}]$, en tanto que la letra $s$ se utiliza para [z], que, como indica la nota de Vatablo, se consideraba el sonido de $z$. Es seguro que esta grafía se debe a Estienne, porque, como se dijo más arriba, aparece ya en la edición de la Biblia de 1528, o sea dos años antes de que Francisco I creara el cargo de lector real de hebreo que desempeñó Vatablo ${ }^{51}$. Probablemente Estienne ha usado o adaptado una manera de representar el sin surgida por aquellos años. Encuentro una grafía casi idéntica en una traducción de la Biblia aparecida un año antes de la primera edición de Estienne. Veamos cómo traduce Iud. 12, 6 el dominico Santes Pagnini:

Et caepit Ghilgad uada larden ī̄. Ephraim. Et fuit, quando dicebant fugitiui Ephraim, transibo, dicebant ei uiri Ghilgad. Nun Ephratae es. Non. dicebantque ei. Dic nun Sciboleth, et dicebat Siboleth. Et non ualebat loqui sic. Et aprehendebant eum, et iugulabant eum in uadis larden 52 .

${ }^{49}$ Alphabetum Hebraicum, Parisiis, ex officina Roberti Stephani, typographi Regii, 1549, f. A iiii v ${ }^{\circ}$. Para comprender la referencia a los judíos de Aviñón téngase en cuenta que esta ciudad fue territorio papal hasta la revolución, y allí pudieron seguir viviendo los judíos después de su expulsión de Francia en el siglo XIv y de Provenza en el Xv; cf. George Jochnowitz, "JudeoRomance languages", en Herbert PAPER (ed.), Jewish languages. Theme and variations, Association for Jewish Studies, Cambridge, MA, 1978, p. 69.

${ }^{50}$ George Jochnowitz, "Shuadit: la langue juive de Provence", Archives Juives, 14 (1978), p. 66; también su "Judeo-Romance" citado en la nota anterior, p. 70.

${ }^{51}$ Elizabeth Armstrong, Robert Estienne, royal printer, Cambridge University Press, Cambridge, 1954, p. 77.

${ }^{52}$ Biblia. Impressa est Lugduni per Antonium du Ry. anno dni. 1.5.2.7, f. $M$ ii $v^{\circ}$ a. 
Pagnini presenta la pronunciación de galaaditas y efraítas como se y $s$, utilizando casi las mismas grafías que Estienne. En dos pasajes se extendió Pagnini sobre las características del sin y el samec. Interesa conocerlos:

Seboleth, scribe Siboleth [sic], Iudicum 12.C etc. est cum sin, id est spica, alueus [...] Seboleth, alias Cheboleth, scribe siboleth Iudic $5 \mathrm{C}$ etc. est cum samech et est densius s quam sin et potest interpretari quam si sibla $[\ldots]$.

(Liber interpretationum nominum hebraicorum, s. v. seboleth, en su edición de la Biblia)
Sin quando habet punctum in dextro cornu hoc pacto $\ddot{w}$ est s lene, communiter legitur sein, et appellatur Sciboleth, quod spicam sonat. Sin vero sit in sinistro hoc modo iv communiter legitur sin densum, videlicet s vt sadi vel samech, et appellatur siboleth alueum notat.

(Hebraicae Institutiones, Lyon, 1526 , p. $6 a)$

Resulta difícil decir qué representa fonéticamente el sin en Pagnini; como una aproximación al tema, observemos que: 1) coincide con Estienne en hacerlo lene frente al samec, y sabemos que para el francés esta sibilante lene era la $s$; y 2) concuerda igualmente con Estienne en hacerlo poseer en menor grado una cualidad más abundante en el samec: la cualidad de "denso" para Pagnini, la "vehemencia" para Estienne. Esto es interesante si se repara en que cuando el sin es palatal, es a él a quien se le da determinada cualidad en más alto grado que al samec (cf. el pasaje de Pedro Martínez de Morentín citado más adelante); parecería, por tanto, que el sin de Pagnini no era sin. Por todo lo dicho me inclino a pensar que Pagnini podría muy bien tener presente un sin predorsal; en cuanto al samec, se hace duro relacionar con un zumbido la cualidad de "denso"; el ceceo, en cambio, sí puede hacer pensar en lo "gordo" o "grueso" y no sería imposible que Pagnini estuviera reproduciendo una oposición [s]-[s,, $\theta]$.

¿Y la grafía sc? Como en el caso de Estienne, se me escapa por qué la usa para la letra cuyo sonido era [s] y, por el contrario, reserva la letra $s$ para la sibilante que sonaba más 'densa". Pero aun sin poder solucionar este problema, queda aclarado un punto valioso tras el examen de los textos de Pagnini: el dominico está descartando conscientemente las grafías tradicionales; él conoce las antiguas formas del siboleth, pero propone reemplazarlas por otras: "Seboleth, scribe Siboleth [...] Seboleth, alias Che- 
boleth, scribe Siboleth' ¿Por qué hay que escribir sciboleth y no seboleth? La cuestión de la sibilante desgraciadamente no quedó aclarada y a esto se suma lo que puede ser una errata en el ejemplo del siboleth con sin, que no aparece escrito sciboleth como en los otros lugares; pero si nos atenemos a la forma que efectivamente usa Pagnini, vemos que tiene dos cambios con respecto a la antigua: no sólo cambia la consonante inicial (o su grafía), sino también la primera vocal de $\varepsilon$ en $i$. Ahora bien, el origen de esta segunda corrección no tiene ningún misterio: en el texto hebreo masorético la puntuación de la palabra indica una vocalización en $i$. Pagnini, pues, está enmendando las formas medievales del siboleth de acuerdo al texto hebreo.

Y, por supuesto, éste es también el origen de las innovaciones de Estienne. El texto que usó para hacer sus ediciones de la Biblia fue el de la Universidad de París, corregido en bastantes pasajes con las lecciones de manuscritos antiguos y respetables ${ }^{53}$. La Vulgata de la Universidad de París tenía esas formas sebbolech thebbolech que hemos visto en Alfonso el Sabio; los códices que consultó Estienne han de haber ofrecido la oposición sebboleth $\sim t(h) e b$ boleth corriente en la Edad Media ${ }^{54}$. No puede caber duda, por

${ }^{53} \mathrm{H}$. Quentin, Mémoire, p. 115.

54 Varios de los manuscritos que utilizó Estienne han podido ser identificados. Se conservan los dos de Saint-Germain-des-Près que manejó (tomo los datos que siguen del aparato crítico de la edición de la Vulgata de los Pp. Benedictinos). El llamado Sangermanense oblongum presenta en Iud. 12, 6 las formas sibboleth $\sim$ sibboleth, que son correcciones sobre unos antiguos sebboleth $\sim$ sebboleth; parecería tratarse, tanto en el original como en las correcciones, de lecciones que no intentan representar gráficamente la diferencia entre las dos sibilantes, sino dar a entender: sebboleth (con sin) sebboleth (con samec). El Sangermanense parvum tiene las formas corregidas sibboleth ( $i$ en lo borrado) zibboleth ( $z i$ en lo borrado). Como la $s$ en la palabra galaadita es originaria, se ve que este manuscrito daba primitivamente al sin la grafia $s$; por ello cabe pensar que seguía la fórmula tradicional y que la consonante raspada en la imitación de la pronunciación efraíta sería $t$ o th. En el margen una anotación dice: "sibboleth p[er] sin zibboleth per zamach". Es posible que esta representación del sin y el samec como $s-z$ corresponda a una oposición de sonoridad; la $z$ se usaba muchas veces como signo de una sibilante fricativa sonora, y el mismo Estienne (o Vatablo) al sentar que el samec suena como nuestra $s$ entre dos vocales en medio de dicción, aclara el punto diciendo que es "quasi pronuntiares ziboleth" (cf. § 6). Bien puede ser, pues, que la corrección del Sangerm. parvum coincida con el valor fonético que Estienne da al $\sin$ y al samec, pero esto no nos permite hablar de una influencia sobre él porque no se conoce la fecha de esas correcciones: ¿qué tal si fueran posteriores a sus Biblias? En realidad, Estienne tiene mayores coincidencias con Pagnini en cuanto a sonidos y gra- 
lo tanto, de que Estienne se apartó deliberadamente de la antigua oposición [s]-[ș, $\theta$ ] para distinguir a galaaditas y efraítas y de que también deliberadamente adoptó la de [s]-[z], que le habrá parecido la verdadera. ¿Por qué le pareció la verdadera? Ya lo podemos imaginar recordando el pasaje más arriba transcripto de su Alphabetum Hebraicum: porque los judíos de Aviñón, cuya pronunciación siguen los franceses, distinguen el sin y el samec de esa manera (o, por lo menos, eso es lo que creía Estienne). Como Pagnini, Estienne corrige la Vulgata de acuerdo al hebreo. Desde luego, el cambio que hizo en las formas del sibboleth no constituye un caso aislado o anómalo en su proceder de editor bíblico; muy por el contrario, está de acuerdo con su criterio para fijar el texto de las Sagradas Escrituras. Es sabido que al colacionar los códices adoptaba como legítima la lección que coincidía con el hebreo ${ }^{55}$; para él - como ha escrito una autoridad en la materia - "le texte hébreu est l'instrument de critique par excellence pour l'établissement du texte de la Vulgate" 56 .

Concluyendo: en Pagnini y Estienne podemos descubrir claramente cómo y por qué empiezan a morir las pronunciaciones medievales del siboleth. Desaparecen cuando se recurre al hebreo para determinar los sonidos del sin y el samec y, a su vez, se recurre al hebreo cuando los primeros pasos de crítica histórica que iniciaron los humanistas, y la inquietud religiosa de entrar en contacto directo con la palabra de Dios, convergieron en una filología bíblica que se volvía a las fuentes y a la "veritas hebraica".

\section{El Siboleth EN LA Vulgata POstridentina}

Es sabido que esta tendencia a basarse en el hebreo fue una de las causas principales de los conflictos de Estienne con la Universidad de París. En España son bien conocidas la oposición que levantó el recurso al texto hebreo y las violentas polémicas en que se vieron envueltos los teólogos llamados “judaizantes". La Iglesia, en efecto, miraba con desconfianza que la fijación del texto de la Biblia quedara en manos de una cultura ajena al cristianis-

fías, pero en el estado presente de la investigación tampoco sería prudente hablar de influencias porque las semejanzas pueden deberse a que ambos están dentro de la misma corriente de hebraísmo.

${ }_{55}^{5}$ H. Quentin, Mémoire, p. 105.

${ }^{56}$ Ibid., p. 108. 
mo y, más en general, temía que la crítica filológica pudiera llegar a transformarse imperceptiblemente en una crítica del dogma. Ocurría que la labor de crítica textual llevaba a un texto de la Biblia distinto de aquél en que había venido basándose su magisterio. La incipiente conciencia histórica del siglo XvI, sin embargo, ya no permitía la inocente indiferencia con la que en la Edad Media se veían las diversas lecciones de los manuscritos de la Biblia y sus errores de copia; inclusive este mismo desorden ponía en peligro la enseñanza de la Iglesia, porque no sólo parecía arbitrario basarse en unos códices y no en otros, sino porque se corría el riesgo de fundarse en códices corruptos. Frente a esta situación el Concilio de Trento (1546) por una parte declaró texto auténtico de la Biblia a la Vulgata latina y, por otra, suplicó al Papa que hiciera de ella una edición tan pura como fuera posible ${ }^{57}$. Mientras en Roma diversas comisiones sucesivas hacían los preparativos de esa edición crítica, aparecieron, en el espíritu del decreto del Concilio de Trento, las dos famosas ediciones de los teólogos de Lovaina: la de Juan Henten (1547) y las de Lucas de Brujas (1574 y 1583). La de Henten se basó en las ediciones de Estienne de 1532 y $1545^{58}$, y las de Lucas de Brujas reprodujeron sin cambiar una palabra el texto de Henten ${ }^{59}$. De esta manera pasaron a las Biblias católicas las formas schibboleth $\sim$ sibboleth (cf. el aparato crítico de la edición de la Vulgata de los PP. benedictinos de Roma), probablemente con las mismas pronunciaciones que les atribuía el finalmente protestante francés, aunque éste sea un punto que no encuentro manera de comprobar.

La preparación del texto purificado de la Vulgata tuvo en Roma su momento final con la comisión nombrada por Sixto $\mathrm{V}$ en 1586. Presidía esta comisión el cardenal Antonio Carafa y se utilizó para los trabajos un ejemplar de la edición de 1583 de los teólogos de Lovaina, o sea que nuevamente quedó como base el texto de Estienne. La comisión del cardenal Carafa modificó, sin embargo, la forma del siboleth; en el Codex Carafianus (el ejemplar de la Biblia lovaniense de 1583 en que la comisión apuntaba sus enmiendas) aparecen en Iud. 12, 6 las formas scibboleth sibboleth. En su edición de 1590 Sixto V ignoró esta corrección e hizo imprimir

${ }^{57}$ Para la historia de la fijación del texto de la Biblia en la Iglesia, cf. P. Hildebrand Höpfl, O.S.B., Beiträge zur Geschichte der Sixto-Klementinischen Vulgata, Freiburg, 1913 (Biblische Studien, t. 18, cuads. 1-3).

${ }^{58}$ H. Quentin, Mémoire, p. 135.

${ }^{59}$ Ibid., pp. 140, 144, 146. 
schibboleth como pronunciación de los galaaditas. La edición de Clemente VIII, que dio el texto auténtico definitivo de la Vulgata, adoptó, en cambio, la enmienda del códice carafiano y fijó para lo sucesivo la oposición en la forma scibboleth sibboleth.

Mi impresión es que al pasar de sch a se la comisión del cardenal Carafa: 1) cambió el valor fonético que el sin tenía en el texto de Estienne y 2) esta corrección se debió a prestar atención al hebreo. En cuanto al primer punto, observemos que dar al $\sin$ y al samec los sonidos de [s] y [z] es sumamente raro. Sólo lo encuentro en Pagnini (acaso), Estienne y Vatablo; inclusive, como se vio, no corresponde a la pronunciación del judeo-provenzal a que Estienne se remite. Tampoco parece que la pronunciación de los judíos de Aviñón haya sido, por lo menos de la manera absoluta en que lo dice Estienne, la que adoptaban los hebraístas franceses. A principios del siglo XvI, en un pasaje citado muchas veces Johann Reuchlin explica que el sonido del sin:

germani per sch. Itali per sci. Galli per x uel ch significare conant. Unde literam sin in Italia scribit scin. Gallia etiam Geltica xin uel chin. et Sueuia schin ${ }^{60}$.

Para Reuchlin, por tanto, el sin sonaba $\operatorname{vin}$ entre los franceses. Esta noticia ha de ser exacta, no sólo por la autoridad del humanista alemán y la verosimilitud de lo que nos dice, sino porque está confirmada por otro testimonio de peso. El navarro Pedro Martínez de Morentín ${ }^{61}$, que había de terminar como calvinista y profesor de hebreo en La Rochelle, hizo sus estudios de esta lengua en la Universidad de París con Joh. Mercerus (Jean Mercier) y Genebrardo con tanto provecho, que a poco tiempo de terminarlos publicó, en 1568, una gramática hebrea en que se refiere de esta manera al sin:

vi proprie sonat pinguius et crassius quam $\Xi$, ut Francis vulgo $c h$, cum dicunt iter, rem, chemin, chose $^{62}$.

Así, por los años 60 del siglo xvi Pedro Martínez aprendió en la Universidad de París la pronunciación palatal del sin que Reuch-

${ }^{60}$ De Rudimentis Hebraicis, Thomas Anshelm, Pforzheim, 1506, p. 8; reimpresión Georg Holms, New York, 1974.

${ }^{61}$ Noticias sobre su vida en PAUL Colomiès, Gallia Orientalis, en Opera, Hamburgo, 1709, pp. 70-71.

62 Grammatica Hebraea, Ex officina Hieronymi Haultini, Rupelle, 1590, p. 20. La primera edición no ha estado a mi alcance. 
lin ha de haber conocido en esa ciudad a fines del siglo xv. Es que, en realidad, esa forma palatal es la que naturalmente puede esperarse: pertenecía a la gramática hebrea y era la propia de la mayoría de las comunidades judías; lo que sí, en cambio, necesita explicación es esa curiosa oposición de sonoridad entre el sin y el samec que traen Pagnini (?), Estienne y Vatablo. ¿Será una reproducción aproximada de la distinción $\mathrm{s}-\theta$ de los judíos provenzales, reemplazando con [z] el sonido interdental inexistente en francés? No hay que olvidar que a principios del siglo xvı el hebraísmo cristiano estaba dando sus primeros pasos, y la interpretación $\sin [\mathrm{s}]$-samec $[\mathrm{z}]$ bien puede haber sido uno de los tanteos de ese periodo inicial; en la segunda mitad de la centuria parece haberse ya generalizado para esas letras la pronunciación canónica hebrea de $\stackrel{v}{s}-s$.

Y la comisión papal que preparó en Roma el texto depurado de la Vulgata, ¿prestaba atención al hebreo como lo hacían los universitarios, los protestantes y también muchos sacerdotes? Podemos contestar con certeza que sí. La tajante oposición al hebreo parece haber sido un fenómeno español. En Italia no se dio y ya la comisión encargada por Pío $V$ de la preparación del texto purificado de la Vulgata (pedida al Concilio de Trento) recomendó las correcciones de acuerdo al texto hebreo, pidiendo sólo cautela al respecto ${ }^{63}$. A este recurso al hebreo se habían opuesto todas las grandes figuras españolas: Cano, Salmerón, Mariana. Su criterio no encontró eco en Roma y el cardenal Carafa y sus colaboradores no hicieron más que seguir una línea ya trazada al tener presente la Biblia hebrea en sus correcciones. El hecho, además, era inevitable, dada la precaria idea que se tenía en el siglo Xvi sobre lo que debía ser una edición crítica. El supuesto con que se trabajaba era la típicamente renacentista "vuelta a las fuentes" y, por lo tanto, cuanto más antiguo era un texto, tanto más legítimo se lo consideraba. El cardenal Carafa manejó este criterio. Su comisión tenía como uno de sus principios el que en caso de divergencia entre los manuscritos de la Vulgata se había de recurrir al texto hebreo, del cual el latino era una traducción, y a las traducciones paralelas, en especial a la Septuaginta ${ }^{64}$. Se pensaba, pues, que la forma más próxima al hebreo era la que contaba con mayores probabilidades de ser la legítima. Por este camino se iba menos a hacer una edición crítica que a buscar la

${ }^{63}$ Cf. Höpfl, Beiträge, p. 91.

${ }^{64}$ H. Quentin, Mémoire, pp. 460-461; también HöPfl, Beiträge, pp. 132-136. 
fidelidad en la traducción, pero, sea lo que fuere, lo cierto es que el principio de Carafa se llevó a la práctica y se pueden citar casos en que los correctores romanos han seguido el texto hebreo contra la tradición latina y en particular contra el Codex Amiatinus, que era el manuscrito que la comisión tenía por guía ${ }^{65}$.

Creo que las pronunciaciones del siboleth en el Codex Carafianus sirven como ejemplo de la importancia decisiva concedida al texto hebreo. Al adoptar las formas scibboleth sibboleth la comisión abandona la versión de los manuscritos latinos, incluida, desde luego, la del Codex Amiatinus, que presentaba la oposición tradicional sebboleth $\sim$ thebboleth (cf. el aparato crítico de la Vulgata de los PP. Benedictinos de Roma). Lo que ha hecho la comisión sixtina es aceptar la lección de Estienne, que, como sabemos, procedía del hebreo; sólo la enmienda ligeramente, y esto lo hace para perfeccionar su correspondencia con la lengua santa. Cambia la grafía sch en $s c$. Ya hemos visto que en la segunda mitad del siglo xvi el sonido que generalmente se atribuía al sin era $s$. Esta pronunciación tenía el sin en Italia en los tiempos de Reuchlin, quien añadía que allí se escribía scin (cf. supra). No parece caber duda de que ésta fuera la situación en los años en que trabajaba la comisión del cardenal Carafa. Poseemos en este punto el testimonio de un hebraísta, el agustino Marco Marini, que a propósito del sin observaba: "Latini non agnoscunt huius elementi pronuntiationem, a qua tamen non longe abest literarum se prolatio, qualis est in scindo et ascendo" "66. La corrección se por sch ha de haber tenido, pues, el propósito de representar una consonante palatal, que la grafía de Estienne no podía indicar para una pronunciación italiana (me parece difícil que la comisión conociera el sonido que le daba Estienne).

${ }^{65}$ H. Quentin, Mémoire, pp. 176-177.

${ }^{66}$ Marco MARINI, Arca Noe, seu Thesaurus Linguae Sanctae novus, Venecia, 1593, citado por AldReTE, Antigüedades, p. 153. CuERvo, "Disquisiciones"' (1 a versión), Obras, t. 2, pp. 270-271, tomó una referencia al samec del pasaje copiado por Aldrete e identificó la obra de donde procedía, pues el español había omitido esta referencia. De Cuervo, a su vez, tomó las líneas sobre el samec Alonso, "Nebrija", p. 33, n. 70, y Pronunciación, t. 1, p. 82. Aldrete llama "Marino" al hebraísta italiano, sin duda basándose en la latinización "Marinus"'; de él adoptó esta forma Cuervo y, tras el bogotano, Alonso. Pero el nombre de la destacada familia de Brescia a que pertenecía este sacerdote era " $\mathrm{Ma}$ rini" y con esta designación figura en los diccionarios y bibliografías especializados. 
8. El origen de la eQuivalencia lat. $S=S A M E C$ CECEOSO DE Nebrija

Después de esta visión de las vicisitudes del siboleth podemos sacar unas conclusiones. Sea la primera la vindicación de Nebrija; nuestro autor no deliraba cuando igualó la pronunciación de los ceceosos con la de los efraítas: durante siglos fue considerado ceceoso el samec y en este punto Nebrija no es más que un eslabón de una tradición multisecular. En segundo lugar, al dejar establecido en firme cuál era el sonido con que Nebrija compara la $c$ tanto de los castellanos como de los ceceosos, queda ya fuera de discusión que el sonido de esta letra tenía para él un timbre ceceante, como de sobra lo hacían ver otras noticias (cf. $\$ 1$ ); esto no quiere decir, por otra parte, que fuera interdental.

En su referencia al samec ceceoso Nebrija se inserta, pues, en una tradición o, dicho más exactamente, en una doble tradición. Existía la línea procedente de la Vulgata de San Jerónimo, que presentaba como un sonido dentalizado al samec de los efraítas (cf. $\S 5)$; también había comunidades hebreas que tenían un samec ceceoso (cf. § 4). La posición de Nebrija ante estas dos tradiciones es la siguiente: él, desde luego, como cristiano (y español; cf. nota 77), es devoto de la Vulgata, pero como humanista busca un texto de ella purificado por la "veritas hebraica", es decir, corregido según el texto hebreo; así, nos anuncia que su dedicación a los estudios bíblicos lo llevará a cotejar los manuscritos de la Vulgata:

[...] qui facile ostendunt quid Hieronymus scriptum reliquerit, si modo consentit aut non discordat ab eo quod in hebraeis graecisque voluminibus habetur ${ }^{67}$.

Está claro, por lo tanto, que Nebrija se va a ajustar a la Vulgata en cuanto coincida con el texto hebreo. Dada esta pauta de conducta, si encontramos en Antonio un samec ceceoso de los efraítas como en la Vulgata, lo que podemos pensar es que mantiene este rasgo porque concuerda con lo que él sabe de los sonidos del hebreo. ¿Qué sabía Nebrija de hebreo? Por propia declaración, no entendía mucho de esta lengua ${ }^{68}$, de modo que cabe pensar que no podía leer las obras de los gramáticos hebreos; en esta situa-

${ }^{67}$ Apologia, f. b ii ro ${ }^{\circ}$ subrayado mío.

${ }^{68}$ Marcel Batalllon, "L'arabe à Salamanque au temps de la Renaissance", Hesp, 21 (1935), p. 5. 
ción, su conocimiento de los sonidos de la lengua santa ha de depender enteramente de las noticias y pronunciaciones de los judíos con quienes trataba, o sea que el hebreo de Nebrija es el hebreo de los judíos españoles. Y bien, lo que se nos alcanza de la pronunciación del hebreo en España no está en contradicción con la existencia del samec dentalizado. La razón para que se diera el samec ceceoso es - según se desprende de lo visto al final del §5- la desaparición de la palatalidad de $\ddot{E}$; si el sin pasa a alveolar, el samec se interdentaliza para no confundirse con él. Ocurre justamente que entre los judíos españoles ya en el siglo XIV se irabía perdido el valor original de $ש$, "if it had ever existed there" 69 . Esta pronunciación alveolar del sin, con lo que podemos suponer un inevitable adelantamiento de la articulación del samec, está atestiguada por un converso coetáneo de Nebrija. Se trata de Alfonso de Zamora, uno de los colaboradores del Cardenal Cisneros en la edición de la Poliglota Complutense. Al final del tomo VI de esta obra apareció una sucinta gramática hebrea debida a su pluma, en la que caracteriza de esta manera al $\sin$ y al samec:

Profertur itaque samach dentibus sicut apud latinos $c$ cum vocali $e$ vel $i[\ldots]$ ש $\boldsymbol{E}^{\dagger}$ sin vero cum apice siboleth profertur sicut apud latinos simplex $f$, sed si predicta littera scriberetur cum puncto ceboleth tune profertur sicut samach ${ }^{70}$.

El samec se pronunciaba "dentibus" y el $\sin$ como la $s$ "apud latinos"; las dos sibilantes se distinguían como dentalizadaalveolar.

Aclarado este punto, podemos entrar en la cuestión principal: cuando Nebrija sale con su despampanante teoría de que griegos y latinos modernos pronuncian mal la $s$, porque entre los antiguos éste era un sonido ceceoso, ¿en qué se basa? El pasaje del Lib. nom. Hebr. es su marco de referencia y ateniéndose a él va a marchar su razonamiento, pero allí San Jerónimo no da ninguna indicación sobre las sibilantes del hebreo en concreto; establece simplemente una gradación entre ellas con respecto a la $s$ latina: el samec es igual; el sin algo diferente y el sade muy distinto. Cuáles eran

${ }^{69}$ Irene Garbell, art. cit., pp. 667-668.

70 Introductiones artis Grammatice Hebraice, f. i v ${ }^{\circ}$ a, en la Biblia de Alcalá, t. 6 (1515). Téngase en cuenta que en el pasaje que he copiado aparece siempre $f$ (menos en final de palabra) donde yo, por simplificar la impresión, he escrito $s$. 
los sonidos de estas letras, Nebrija no lo podía saber por San Jerónimo. Si, razonando sobre este esquema, asienta que la $s$ latina debía ser ceceosa puesto que era igual al samec, es porque ya sabe que el samec era ceceoso. Es decir, ha leído el pasaje de San Jerónimo con una mente provista de las noticias de los sonidos del hebreo entre los judíos españoles. En su interpretación de San Jerónimo, Nebrija, como declaraba en el pasaje de la Apologia copiado al comienzo de este parágrafo, le hace decir lo que concuerda con el hebreo (tal como él lo conocía) ${ }^{71}$.

Pero - se argüirá acaso- en su traducción del episodio de galaaditas y efraítas San Jerónimo ha dado sus pronunciaciones co-

71 Ya Cuervo, "Disquisiciones" (2a versión), Obras, t. 2, p. 418, había visto que al hacer ceceosa a la $s$ latina equivalente al samec, Nebrija "juzgaba del valor de $D(s)$ por el efecto que le producía en boca de judios". Alonso, "Nebrija", p. 21, n. 36, lo contradice, afirmando que "Nebrija no sigue aquí a su oído, sino a autoridades antiguas, en especial la de San Jerónimo". Esto es imposible, porque, como se dijo en el texto, San Jerónimo no da sonidos a las eses hebreas. En "Nebrija", pp. 31-32, Alonso discute la equivalencia $\xi=$ samec de Nebrija. Nos dice que para comprenderla no hay que partir del valor de $s$ que hoy tiene el samec, sino del valor "reconstruido" por conjetura que Nebrija daba al sonido. Alonso no da ninguna prueba de que Nebrija diera al samec una pronunciación de gabinete, no real. El origen de esta curiosa tesis debe estar en que Alonso había sentado que, por ser el hebreo una lengua muerta, los sonidos que se le atribuían en el Renacimiento no eran más que interpretaciones ("reconstrucciones") de los varios hebraístas (cf. Pronunciación, t. 2, pp. 210-211, 217-218). Pero esto es sacar conclusiones desaforadas del carácter de lengua muerta del hebreo. Seguía viviendo como lengua litúrgica y cada comunidad tenía su tradición de cómo debían pronunciarse las letras; inclusive se escribía (por ejemplo, la poesía hebraico-española) y Alfonso de Zamora hasta lo hablaba (cf. M. BATAILlon, "L'arabe à Salamanque", pp. 5-6). La tesis de Alonso está en contradicción total con los datos. Es sabido que los primeros hebraístas aprendieron la lengua con judíos; de Nebrija sabemos que se trataba con éstos (cf. $n$. 3) y ciertamente tenía una experiencia real de la lengua porque recomendaba escuchar a griegos, hebreos y árabes para saber pronunciar correctamente algunas letras que no existían en castellano; cf. P. Lemus y RuBio, "La Segunda Repetitio del Nebrissense", RABM,

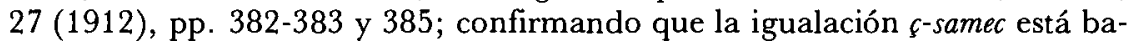
sada en un sonido hebreo, no en una "reconstrucción" conjetural, está el que Alfonso de Zamora, un converso que ha de haberse educado en la escuela rabínica de Zamora, hace la misma equivalencia (cf. el pasaje de su gramática copiado en el $\S 8$ ). En fin, ¿ ¿sobre qué bases iba Nebrija a "reconstruir" el samec si su conocimiento del hebreo muy probablemente no le alcanzaba para leer una obra escrita en esta lengua? La desdichada idea de que Nebrija se refiere a una pronunciación artificial del hebreo lleva a Alonso a despeñarse al interpretar textos de nuestro humanista, pero para el propósito de este trabajo no es necesario entrar en este tema. 
mo sebboleth $\sim t(h)$ ebboleth; por lo tanto, Nebrija muy bien puede haber aprendido que el samec era ceceoso por la representación th que tiene en Iud. 12, 6. Pero el samec ceceoso de Nebrija no ha de venir de la Vulgata por una simple razón: Nebrija actúa sobre la base de que el samec tenía el sonido de $s$; en la Vulgata es el sin el que se representa por $s$, de modo que el samec que se le opone no corresponde a esta letra. Con la transcripción jeronimiana del siboleth Nebrija no podía fundar su teoría de que la $s$ latina era ceceosa porque equivalía al samec ${ }^{72}$.

72 Debo confesar que encuentro una invencible contradicción entre las formas del siboleth en Iud. 12, 6 y las declaraciones de San Jerónimo en el Lib. nom. Hebr. sobre las correspondencias entre la $s$ latina y las sibilantes hebreas (cf. \$ 1); con esas declaraciones concuerda también lo que dice el Lib. Hebr. Quaest. in Gen., C. C., t. 72, p. 34. En el Lib. nom. Hebr. indica que el samec suena como la $s$ latina. Por lo tanto, se esperaría que en la escena de galaaditas y efraítas usara la $s$ para transliterarlo y que para el sin, que difería de $s$, forjara un signo peculiar. Sin embargo, lo que hace San Jerónimo es lo opuesto: pone la $s$ para el sin y al samec lo representa por th, que era su transcripción del tau (cf. Alexander SPERBer, "Hebrew based upon Greek and Latin transliterations', $H U C A, 12 / 13$ (1937-1938), pp. 267-269). Creo que lo que requiere explicación son las formas sebboleth $\sim t(h)$ ebboleth de la Vulgata; si bien es cierto que en su comparación entre la $s$ latina y las $s s$ hebreas San Jerónimo no indica los sonidos en juego, no parece posible que hubiera considerado ceceoso al samec, porque al decir que sonaba como la $s$ latina tendría entonces que haber pensado que ésta era igualmente ceceosa. Nebrija, en la filología primitiva del temprano siglo XVI, pudo sacar esta conclusión, pero no resulta posible atribuir esta idea a un hablante nativo de latín del Imperio Romano. Entre los trabajos que estudian la pronunciación del hebreo registrada por San Jerónimo, unos no tienen en cuenta las transcripciones del siboleth al estudiar las sibilantes; así CARL Siegfried, "Die Aussprache des Hebräischen bei Hieronymus"', Zeitschrifth für die 'Alttestamentliche Wissenschaft, 4 (1884), pp. 66-67, y JAMES BARR, "St. Jerome and the sounds of Hebrew", Journal of Semitic Studies, 12 (1967), pp. 23-28; otros se refieren de pasada a Iud. 12, 6, sin advertir una contradicción entre las transliteraciones que allí se hacen y sus interpretaciones del sin hebraico. A. SPERBER, art.cit., pp. 115, 150, asienta que Jerónimo no distingue entre iv y $\bullet$ ( $i n$ y shin) y llama "efraíta" a su pronurIciación con el solo $ש(\sin )$. EDMuND F. Sutcliffe. S. J., "St. Jerome's pronounciation of Hebrew", Biblica, 29 (1948), pp. 121-122, también cree que el hebreo de San Jerónimo conoce una sola $v$, pero, al revés de Sperber, estima que representa al shin, no al sin. El santo la translitera como $s$ porque el alfabeto latino no tenía equivalente para el shin; sin embargo - añade el P. Sutcliffe- cuando quiere señalar su diferencia con el samec ( $=$ iv ) como en Iud. 12, 6, emplea los recursos lingüísticos necesarios. Pero lo que ocurre cuando San Jerónimo quiere distinguir entre $\ddot{v}$ y $D\left(=v^{j}\right)$ es que se reserva la $s$ para el presunto shin y no para el sin, lo que no da sentido con la explicación del jesuita inglés. Tampoco cuadra su proceder con la explicación de Sperber, porque el supuesto $U(\sin )$ efraíta es transcrito con $t$, no con $s$. 


\section{El hebraísmo de Nebrija}

La atención al hebreo de Nebrija se muestra no sólo en el sonido que asigna al samec, sino en la vocal $i$ que usa en la primera sílaba de siboleth. Esta forma con $i$ procede de la vocalización de la palabra en la escritura masorética. Es la que se impone en el Renacimiento, reemplazando a las medievales sebboleth $\sim t(h)$ ebboleth de la Vulgata. Aparece tan pronto como se empieza a traducir el texto hebreo de la Biblia; la hemos visto en la versión de Pagnini (cf. § 6) y podemos añadir ahora que en España ya en la primera mitad del siglo XIV se encuentran las formas syoboleth $[$ sic $] \sim$ ciboleth en una traducción de la Biblia hecha directamente del hebreo ${ }^{73}$. Se recordará que, sin embargo, en una obra de inspiración tan moderna como la Poliglota Complutense se han mantenido las formas con $e$ del siboleth (cf. $\S 5$ ). Esto nos conduce a un interesante problema. Es sabido que Nebrija abandonó su participación en la Biblia de Alcalá por una diferencia de criterios con el Cardenal Cisneros; conocemos bien el episodio porque lo narró el mismo Nebrija en una carta a la que quiso dar la mayor circulación posible. Según nos cuenta nuestro humanista, él quería corregir el texto de acuerdo al griego y al hebreo; las directivas del Cardenal fueron, en cambio, que se limitara a elegir las mejores lecciones de los textos latinos, tal como hacían las helenistas con respecto a los textos griegos y los hebraístas con los hebreos ${ }^{74}$. Se opone,

${ }^{73}$ Bible (Old Testament) translated from the Hebrew into Castillan by Rabbi Moses Arragel de Guadalfajara (1422-1433?), and published by the Duke of Berwick and Alba, Madrid, 1918, t. 1, p. 614.

74 "Epístola del Maestro de Lebrija al Cardenal", $R A B M, 8$ (1903), p. 493. No es éste el lugar para discutir las directivas de Cisneros en su edición de la Biblia, que tan mal condicen con su antiguo interés personal por el hebreo, su preocupación por hacerlo formar parte de la cultura teológica y, para mayor paradoja, con su recomendación de recurrir al texto hebreo para corregir los errores de los manuscritos latinos, que estampa en la dedicatoria de la Poliglota a Leon X, vol. 1, f. iii $\mathrm{r}^{\circ}$ a. El mismo Nebrija, que conocía de años atrás esta veta de su protector, evidentemente fue sorprendido por ese criterio editorial: "[...] cuando vine de Salamanca, Yo degé alli publicado, que venia a Alcalá para entender en la emendacion del Latin, que está comunmente corrompido en todas las Biblias Latinas cotejandolo con el Hebraico, Caldaïco, i Griego" (ibid., p. 493). Es obvio que no esperaba encontrar en Cisneros la disposición espiritual que en el texto llamo "teológica"; al fin, el Cardenal no sólo había permitido la publicación sino inclusive había aceptado la dedicatoria de la Tertia Quinquagena, en que Nebrija practica ese criterio de enmendar la Biblia de acuerdo con el griego y el hebreo que ahora se le prohíbe. Lo cierto es que el Cardenal no le da ninguna explicación a Ne- 
pues, el criterio humanista de Nebrija al teológico del Cardenal. Fundándose en textos de San Agustín, De doctr. Christ., II, 11, y de San Jerónimo, Epist. CVI, ad Suniam et Fretelam, muy citados por los editores del Renacimiento, Nebrija había sostenido la teoría

brija, señal tanto de que para él éste era un punto no negociable como de que consideraba inútil razonar la cuestión con el humanista, y sólo le insiste con benevolencia "que hiciesse aquello mesmo, que a los otros avia mandado". Pero, desde luego, bueno era Nebrija para "hacer lo mesmo, que a los otros se avia mandado" y prefiere retirarse de la empresa antes que abdicar su libertad intelectual. Un dato más de este mal conocido episodio lo constituye el que cinco correcciones a la Biblia de la Quinquagena de Nebrija, que no fueron incorporadas al texto latino de la Poliglota, sí aparecen, en cambio, en los vocabularios correspondientes (cf. CARLOS Gilly, Spanien und der Basler Buchdruck bis 1600, Helbing \& Lichtenhahn, Basel-Frankfurt, 1985, p. 149). Jerry H. Bentley, Humanists and Holy Writ. New Testament scholarship in the Renaissance, Princeton University Press, Princeton, NJ, 1983, pp. 89-91, presenta el conflicto de Cisneros con Nebrija como si los helenistas y hebraístas del "editorial team" de la Poliglota hubieran acusado al humanista de excederse en sus atribuciones al corregir el texto latino según el griego y el hebreo. El Cardenal habría determinado entonces que cada uno se limitara a los manuscritos de la lengua de su especialidad. Ahora bien, no hay nada en la carta de Nebrija que permita suponer, siquiera vagamente, una disputa entre él y los otros colaboradores de la Poliglota, y que Cisneros hubiera actuado de juez en ella. Me parece que Bentley da demasiado peso a los editores de la Biblia de Alcalá; habla de que ésta "reflects their values" (p. 91) y de que eran "an extremely conservative circle" (p. 110). Pero los editores no eran un "committee" " de "independent scholars", del cual Cisneros era un "chairman", que cada tanto debía intervenir para solucionar una crisis surgida en algún agitado "meeting" de irritables intelectuales. Cisneros no era chairman, sino el señor, a quien los editores debían servir. El Cardenal imponía sus criterios y quien no los aceptaba, como ocurrió con Nebrija, no tenía lugar en la empresa. Nunca se les hubiera ocurrido a los editores querer hacer valer sus ideas en la obra. El mismo Nebrija, con la fuerte personalidad que tenía, cuando el Cardenal le dice que se atenga a los manuscritos latinos, lo único que hace es retirarse respetuosamente: ni piensa sostener su punto de vista frente a él. Nebrija choca con Cisneros, no con sus compañeros de trabajo, que no contaban para los criterios editoriales. Al mismo Bentley, pp. 100-105, se debe un interesante estudio de cómo en una lista de diferentes lecciones del texto griego del Nuevo Testamento, una mano posterior señaló las que coincidían con las de la Vulgata; las lecciones indicadas por esa mano son las que se imprimieron en el texto griego de la Complutense. Sobre el trabajo del equipo, pues, se producía después una revisión y selección de acuerdo con determinados criterios editoriales, que, según nos muestran éste y otros ejemplos, tenía por fin defender el texto de la Vulgata. Estos criterios editoriales superiores, como permite entrever la carta de Nebrija, habrían de venir del Cardenal. En el $\S 9$ refiero a propósito de Alfonso de Zamora lo que puede ser otro caso de directivas impuestas a los colaboradores; el propósito siempre es mantener la vigencia de la Vulgata. 
del "recurso a la lengua precedente" para corregir los textos de la Vulgata: en casos de variedad de lecciones entre los textos latinos del Nuevo Testamento, hay que recurrir al griego; en caso de diferencia de lecciones de los manuscritos latinos del Viejo Testamento entre sí o con respecto al griego, hay que recurrir al hebreo ${ }^{75}$. Desde luego, las recomendaciones de acudir al griego y al hebreo tenían para San Jerónimo y San Agustín un sentido muy diferente del que adquirían al ser esgrimidas en el Renacimiento; utilizarlas como criterio en esta época era convertir al hebreo en árbitro de lo que decía la Biblia y suscitar inevitablemente las resistencias de que más arriba se habló (cfi § 7). Es que los humanistas desacralizaban la Vulgata y la trataban como si no fuera más que una traducción, cuyo valor se medía por la fidelidad con que reflejaba la "veritas hebraica".

Para Cisneros, evidentemente, lo fundamental de la Vulgata era su valor doctrinal; era el libro de la Iglesia, en que ésta había venido fundando su magisterio desde hacía siglos. Era más que un texto en el flujo del tiempo: representaba la verdad. Por ello, muy consecuentemente, la actitud del Cardenal constituye la inversión de la teoría del "recurso a la lengua precedente" y concede la posición privilegiada a la versión latina de la Biblia (según la cual, si llega a ser necesario, se corrige el texto en otra lengua):

Medium autem inter eas [la versión hebrea a la izquierda y la griega a la derecha] latinam beati Hieronymi translationem velut inter Synagogam et Orientalem Ecclesiam posuimus: tanquam duos hinc et inde latrones medium autem Iesum hoc est Romanam siue Latinam Ecclesiam collocantes ${ }^{76}$.

Efectivamente, en la Poliglota Complutense los textos no están presentados en progresión cronológica, sino que, ocupando el centro del folio, está la Vulgata de San Jerónimo y hacia am-

75 "Regula uero uiaque castigandi illa nimirun est: quam idem Augustinus cum alijs compluribus in locis: tum in eodem secundo atque etiam in tertio de doctrina christiana volumine tradit. Quamque diuus Hieronymus in omnibus prologis, epistolis, commentationibus reliquisque operibus suis, quamdemque omnes prisci atque proinde sanctissimi doctores tradiderunt: $\mathrm{Vt}$ quoties in testamento nouo inter libros latinos fuerit reperta varietas, recurramus ad graecos, quoties inter latinos inter se aut inter latinos et graecos in testamento veteri fuerit aliqua differentia, certitudinem petamus ex veritate fontis hebraicae. Itaque semper in dubiis ad linguam precedentem eundum esse praecipiunt'" (Apologia, f. a $1 \mathrm{v}^{\mathbf{o}}$ ).

${ }^{76}$ Poliglota Complutense, "Prologus ad lectorem”, t. 1, f. iii vo a. 
bos márgenes se aprietan los textos griego y hebreo. La simbología sagrada no podía estar mejor expresada que por esa imagen de que el texto latino está como Cristo entre los dos ladrones. Dada esta jerarquía entre los tres textos, se comprende por qué la Vulgata medieval se siguió imprimiendo en España hasta fines del siglo XVI, es decir, hasta el momento mismo en que Roma promulgó la nueva versión de la obra ${ }^{77}$. El apego al viejo texto es más que un mero arcaísmo: es una manifestación de ortodoxia; así se mostraba la adhesión a una Biblia no profanada ni sospechosamente alterada por judaizantes y reformadores. Esos $s e-$ boleth y ceboleth que están en la Biblia de Alcalá y otros textos de la época han sido impuestos por acción oficial. Si no hubiera mediado el veto de Cisneros, muy probablemente Nebrija hubiera "enmendado" los manuscritos de la Vulgata con la forma hebraizada siboleth, que, como se vio, era la que él personalmente usaba. Me parece que hay otro caso que indica que han de haber sido las directivas de Cisneros lo que impidió la aparición de la forma siboleth en la Poliglota. Más arriba ( $(8)$ me he referido a la gramática hebrea de Alfonso de Zamora, uno de los hebraístas del equipo del Cardenal, publicada al final del tomo VI del trabajo. Al tratar de las sibilantes llama sin "cum apice seboleth" al que lo tiene a la derecha, y sin "cum apice ceboleth" al que lo lleva a la izquierda ${ }^{78}$. Alfonso, pues, "no innova" aquí (como quería el Cardenal) en el vocalismo de la palabra, pero cuando once años más tarde publica por su cuenta una gramática hebrea ya usa la forma hebraizada ciboleth $^{79}$.

En cuanto a la Biblia Regia de Amberes, el proyecto originario del equipo de Plantino era dar como versión latina la de Pag-

${ }^{77}$ La defensa de la Vulgata de San Jerónimo se dio principalmente en España. Los teólogos hispanos le concedían valor absoluto y rechazaban las versiones griega y hebrea. Se ha podido hablar de "spagnolismo" a propósito de esta lucha por la Vulgata (cf. Hopfl, Beiträge, p. 40); acaso no sea más que una de las últimas manifestaciones de la "devotio iberica". Al cabo del Concilio de Trento y de las largas discusiones siguientes, se impuso en la Iglesia el criterio de una autoridad de la Vulgata limitada a las cuestiones de fe y moral y se consideró que en todo lo que no tocara estos puntos los textos griego y hebreo eran igualmente auténticos. Una buena exposición de estas discusiones sobre la Vulgata se encuentra en H. Hopfl, Beiträge, pp. 1-43.

${ }^{78}$ Introductiones artis Grammatice Hebraice, $\mathrm{f}, 1 \mathrm{v}^{\circ}$ a, en la Biblia de Alcalá, t. 6 (1515). Los términos aparecen seis veces, una de ellas figura como siboleth; frente a las otras cinco formas con $e$, interpreto el caso como un error o desliz.

${ }^{79}$ Introductiones artis Grammatice Hebraice nunc recenter edite, Alcalá, 1526, ci-

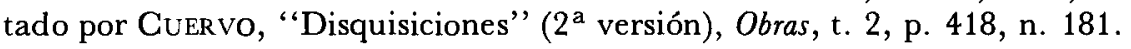


nini, o sea una traducción moderna del hebreo ${ }^{80}$. Felipe II se opuso a la sustitución de la Vulgata e instruyó terminantemente a Arias Montano, su representante en los trabajos de edición de la obra:

[...] haréis que la dicha edición Vulgata se ponga y quede en el mesmo lugar que está en la Biblia complutense por la auctoridad que tiene en toda la Iglesia universal, y porque siendo como es la más principal de todas las versiones, no fuera justo que faltara ni se dejara de poner en una obra tan insigne y en el principal lugar de ella ${ }^{81}$.

Montano, que consideraba trabajo perdido y aun dañoso enmendar la Vulgata ${ }^{82}$, pero que no estaba hecho de la madera de Nebrija, acató la orden del rey y la hizo imprimir en la Poliglota de Amberes; no por eso renunció a la versión de Pagnini que quería Plantino (y él mismo) y la publicó en el tomo octavo como traducción interlinear del texto hebreo. También dio una versión latina de la Septuaginta, de modo que en la Biblia Regia hay tres textos latinos; todo esto evidentemente se halla en contra del espíritu de la instrucción real, que buscaba destacar el carácter único de la Vulgata. Montano desvirtuó igualmente la recomendación de colocar a la Vulgata en el lugar principal, tal como estaba en la Biblia Complutense. Publicó cuatro textos en cuatro columnas; de izquierda a derecha: hebreo, Vulgata, traducción latina de la Septuaginta y el texto griego de ésta. Siendo cuatro los textos, no hay por lo tanto un lugar central; existe sólo una zona central reservada a las traducciones latinas. En este espacio medio la Vulgata aparece apareada a la traducción latina de los LXX, es decir, está sutilmente degradada al papel secundario de traducción del original a su izquierda, tal como la otra versión latina lo es del original que se halla a la derecha. En su prólogo al lector Montano remeda vagamente lo que había dicho Cisneros en el suyo, pero algunas palabras u omisiones dejan entrever la gran distancia

${ }^{80}$ B. Rekers, Benito Arias Montano (1527-1598), The Warburg Institute, University of London, London, 1972, p. 48.

81 "Instrucción al Doctor Benito Arias Montano", del 25 de marzo de 1568, en Tomás González Carvajal, "Elogio histórico del doctor Benito Arias Montano", Memorias de la Real Academia de la Historia, 7 (1832), p. $142 a$.

${ }^{2}$ Cf. Natalio Fernández Marcos y Emilia Fernández Tejero, "Biblismo y erasmismo en la España del siglo XVI", en El erasmismo en España, Santander, 1986, p. 102. 
que en realidad lo separaba de él. Así, comienza elogiando significativamente el texto hebreo de la izquierda, al que llama la "Hebraica veritas"; después de señalar que los LXX tienen una "Latina interpretatio" añade que "his [a estos textos] additur Vulgata editio, Sancto Hieronymo plerumque adscripta", o sea se menciona a la Vulgata después de una traducción (el lector establecerá por sí mismo la relación) y se le quita seriedad al decir que plerumque 'muchas veces' se atribuye a San Jerónimo: el valor consagrado queda reducido a la opinión de mucha gente ( $i y$ qué valor se puede dar a la opinión de la gente?). Cierra su párrafo Montano con una aparente paráfrasis de Cisneros, señalando que la Vulgata "inter Hebraeum et Graecum textum medium obtinet locum". Ya he mostrado cuál es ese "medio" que Montano da a la traducción "atribuida" a San Jerónimo; obsérvese que no destaca, como hacía Cisneros, el papel simbólico que tenía la posición central y que, por supuesto, omite su comparación de los textos en las tres lenguas con Cristo entre los dos ladrones ${ }^{83}$.

Evidentemente, Montano cumplió a disgusto la orden de publicar la Vulgata, pero la obedeció porque sabía la importancia que se daba a la cuestión en España. Sin duda aleccionado por su experiencia editorial de Amberes y, sobre todo, por la tempestad que se le descargó tras la publicación de la Biblia, todavía en su obra sobre el Libro de los jueces (1592) reproduce intacto el texto de la Vulgata con sus seboleth ceboleth en Iud. 12, 6, por más que en su comentario use las ya vistas formas siboleth $\sim$ zziboleth, çiboleth.

Llegados al fin del camino, podemos ver que las noticias sobre sonidos que nos da el siboleth de Nebrija están reflejando las tensas vicisitudes del biblismo y hebraísmo españoles del siglo xvi. El llorado Amado Alonso había visto en él una ociosa "referencia erudita"; si lo consideramos como la referencia histórica que es: testimonio de la vida e ideas de una época, se desprenden de él valiosas informaciones fonéticas y culturales.

Guillermo L. Guitarte Boston College

${ }^{83}$ Cf. Biblia Regia, t. 1, "Eiusdem Benedicti Ariae Montani alia ad lectorem praefatio", sin foliación. 